\title{
Superparamagnetic iron oxide nanoparticles: magnetic nanoplatforms as drug carriers
}

\author{
This article was published in the following Dove Press journal: \\ International Journal of Nanomedicine \\ 5 July 2012 \\ Number of times this article has been viewed
}

\author{
Wahajuddin ${ }^{1,2}$ \\ Sumit Arora ${ }^{2}$ \\ 'Pharmacokinetics and Metabolism \\ Division, CSIR-Central Drug \\ Research Institute, Lucknow, \\ Uttar Pradesh, ${ }^{2}$ Department of \\ Pharmaceutics, National Institute \\ of Pharmaceutical Education and \\ Research, Rae Bareli, India
}

\begin{abstract}
A targeted drug delivery system is the need of the hour. Guiding magnetic iron oxide nanoparticles with the help of an external magnetic field to its target is the principle behind the development of superparamagnetic iron oxide nanoparticles (SPIONs) as novel drug delivery vehicles. SPIONs are small synthetic $\gamma-\mathrm{Fe}_{2} \mathrm{O}_{3}$ (maghemite) or $\mathrm{Fe}_{3} \mathrm{O}_{4}$ (magnetite) particles with a core ranging between $10 \mathrm{~nm}$ and $100 \mathrm{~nm}$ in diameter. These magnetic particles are coated with certain biocompatible polymers, such as dextran or polyethylene glycol, which provide chemical handles for the conjugation of therapeutic agents and also improve their blood distribution profile. The current research on SPIONs is opening up wide horizons for their use as diagnostic agents in magnetic resonance imaging as well as for drug delivery vehicles. Delivery of anticancer drugs by coupling with functionalized SPIONs to their targeted site is one of the most pursued areas of research in the development of cancer treatment strategies. SPIONs have also demonstrated their efficiency as nonviral gene vectors that facilitate the introduction of plasmids into the nucleus at rates multifold those of routinely available standard technologies. SPION-induced hyperthermia has also been utilized for localized killing of cancerous cells. Despite their potential biomedical application, alteration in gene expression profiles, disturbance in iron homeostasis, oxidative stress, and altered cellular responses are some SPION-related toxicological aspects which require due consideration. This review provides a comprehensive understanding of SPIONs with regard to their method of preparation, their utility as drug delivery vehicles, and some concerns which need to be resolved before they can be moved from bench top to bedside.
\end{abstract}

Keywords: superparamagnetic iron oxide nanoparticles, SPIONs, targeted delivery, coating, functionalization, targeting ligands, toxicity

\section{Introduction}

All great things come in small packages, and products of nanoscience are no exception. Nanoparticles are simply particles in the nanosize range $\left(10^{-9} \mathrm{~m}\right)$, usually $<100 \mathrm{~nm}$ in size. Due to their small size and surface area characteristics, they exhibit unique electronic, optical, and magnetic properties that can be exploited for drug delivery. Also known as nanovectors in the field of drug delivery, they are promising new tools for controlled release of drugs because they can satisfy the two most important criteria for successful therapy, ie, spatial placement and temporal delivery.

No drug is free from side effects, and these side effects usually arise from nonspecificity in drug action. For instance, in the case of tumor therapy, it is the side effects of cytotoxic drugs, such as bone marrow depression and reduced immunity, which can be hazardous to the extent that termination of therapy may be required. Modification 
of the surface characteristics of nanoparticles, such as superparamagnetic iron oxide nanoparticles (SPIONs) with biocompatible polymers, and controlling their size within the desirable range can yield powerful targeted delivery vehicles which can deal with this issue.

Freeman et al were the first to introduce the concept of use of magnetism in medicine in the 1970s. ${ }^{1}$ Since then, much research has been done in this area, leading to the design of various magnetic particles and vectors. The main objective today is optimization of the properties of these magnetic particles to: provide an increase in magnetic nanoparticle concentration in blood vessels; reduce early clearance from the body; minimize nonspecific cell interactions, thus minimizing side effects; and increase their internalization efficiency within target cells, thus reducing the total dose required., ${ }^{2,3}$

SPIONs are small synthetic $\gamma-\mathrm{Fe}_{2} \mathrm{O}_{3}$ (maghemite), $\mathrm{Fe}_{3} \mathrm{O}_{4}$ (magnetite) or $\alpha-\mathrm{Fe}_{2} \mathrm{O}_{3}$ (hermatite) particles with a core ranging from $10 \mathrm{~nm}$ to $100 \mathrm{~nm}$ in diameter. In addition, mixed oxides of iron with transition metal ions such as copper, cobalt, nickel, and manganese, are known to exhibit superparamagnetic properties and also fall into the category of SPIONs. However, magnetite and maghemite nanoparticles are the most widely used SPIONs in various biomedical applications. SPIONs have an organic or inorganic coating, on or within which a drug is loaded, and they are then guided by an external magnet to their target tissue. These particles exhibit the phenomenon of "superparamagnetism", ie, on application of an external magnetic field, they become magnetized up to their saturation magnetization, and on removal of the magnetic field, they no longer exhibit any residual magnetic interaction. This property is size-dependent and generally arises when the size of nanoparticles is as low as $10-20 \mathrm{~nm}$. At such a small size, these nanoparticles do not exhibit multiple domains as found in large magnets; on the other hand, they become a single magnetic domain and act as a "single super spin" that exhibits high magnetic susceptibility. Thus, on application of a magnetic field, these nanoparticles provide a stronger and more rapid magnetic response compared with bulk magnets with negligible remanence (residual magnetization) and coercivity (the field required to bring the magnetism to zero). ${ }^{4,5}$ This superparamagnetism, unique to nanoparticles, is very important for their use as drug delivery vehicles because these nanoparticles can literally drag drug molecules to their target site in the body under the influence of an applied magnet field. Moreover, once the applied magnetic field is removed, the magnetic particles retain no residual magnetism at room temperature and hence are unlikely to agglomerate (ie, they are easily dispersed), thus evading uptake by phagocytes and increasing their half-life in the circulation. Moreover, due to a negligible tendency to agglomerate, SPIONs pose no danger of thrombosis or blockage of blood capillaries.

The current research on SPIONs is opening up broad horizons for their use in the biomedical sciences. They have been used for both diagnostic as well as therapeutic purposes. In magnetic resonance imaging (MRI), SPIONs have been used as targeted magnetic resonance contrast agents, allowing diagnosis of progressive diseases in their early stages. ${ }^{6}$ From a drug delivery point of view, targeting of cancer is the most pursued area, with emphasis on delivery of chemotherapeutics and radiotherapeutics. ${ }^{7,8}$ However, increasing applications of SPIONs have also been found in the areas of gene delivery, cell death with the help of local hyperthermia, and delivery of peptides and antibodies to their site of action.

Toxicity is an important issue which must be dealt with before SPIONs can be considered for widespread use in drug delivery. Much research has been carried out to evaluate the biocompatibility of these magnetic nanoparticles and their possible adverse interactions with cellular and subcellular structures..$^{9,10}$ In this review, we discuss their desirable characteristics, including shape, hydrodynamic volume, surface charge and colloidal stability, various methods used for preparation of these nanoparticles, and their role in the biomedical sciences. Furthermore, limitations of SPIONs as drug delivery agents and their toxicity are discussed in detail.

\section{Physicochemical characteristics essential for drug delivery}

Figure 1 shows the most important physicochemical characteristics of SPIONs, which should be taken into account while designing a successful drug delivery system. Such properties mostly govern the blood distribution profile of these nanoparticles.

\section{Shape}

The morphology of $\mathrm{Fe}_{2} \mathrm{O}_{3}$ nanoparticles has been known to be affected by several factors, including the reaction conditions and chemicals involved. In the presence of surfactants with bulky hydrocarbon chain structures, like oleylamine and adamantane amine, the steric hindrance exerted by surfactants has been shown to affect the shape of growing crystals of iron oxide during synthesis. ${ }^{11}$ The shape of magnetic nanoparticles has not been extensively studied as far as its effect on biodistribution of SPIONs is concerned. However, a few 


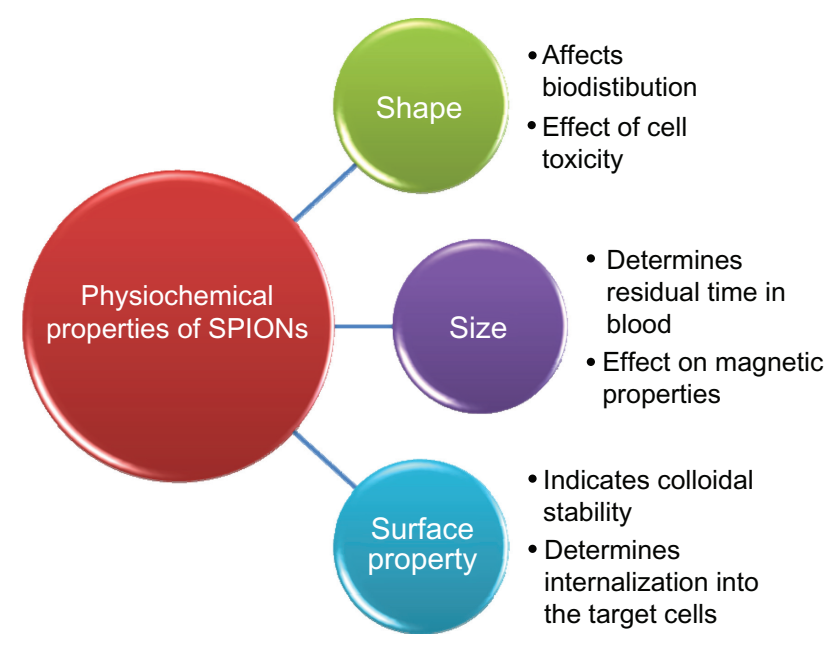

Figure I Physicochemical considerations of superparamagnetic iron oxide nanoparticles for drug delivery.

researchers studying other nanoparticulate delivery systems have reported that rod-shaped and nonspherical nanoparticles show a longer blood circulation time compared with spherical particles. ${ }^{12}$ For instance, Huang et al studied the effect of particle shape on the in vivo behavior of mesoporous silica nanoparticles. They found that the shape of the nanoparticles could affect their biodistribution, clearance, and biocompatibility in vivo. Short-rod mesoporous silica nanoparticles which are more or less spherical were found to accumulate in the liver, whereas long-rod-shaped particles were distributed to the spleen. Moreover, short-rod mesoporous silica nanoparticles showed rapid clearance rates via urine and feces compared with long-rod mesoporous silica nanoparticles. ${ }^{12}$ Another reason which may favor a longer blood circulation time for rod-shaped nanoparticles may be the fact that the phagocytic activity of macrophages is stimulated to a lesser extent by rod-shaped particles than by spherical ones. ${ }^{13}$ However, spherical magnetite and maghemite particles offer a uniform surface area for coating and conjugation of targeting ligands or therapeutic agents. Mahmoudi et al showed that the shape of SPIONs exerts a direct effect on cell toxicity. Nanobeadshaped, nanoworm-shaped, and nanosphere-shaped SPIONs showed greater cellular toxicity compared with nanorods and colloidal nanocrystal clusters. ${ }^{14}$

\section{Size}

The size of nanoparticles largely determines their half-life in the circulation. ${ }^{15}$ For instance, particles with sizes smaller than $10 \mathrm{~nm}$ are mainly removed by renal clearance, whereas particles larger than $200 \mathrm{~nm}$ become concentrated in the spleen or are taken up by phagocytic cells of the body, in both instances leading to decreased plasma concentrations.
However, particles with a size range of 10-100 $\mathrm{nm}$ are considered to be optimum, with longer circulation times because they can easily escape the reticuloendothelial system in the body. They are also able to penetrate through very small capillaries. ${ }^{16}$ Furthermore, biomedical applications of SPIONs, including MRI, hyperthermia, and magnetic cell separation, depend on the magnetic properties of these particles, which in turn are largely dependent upon size. ${ }^{15}$ The small size of SPIONs is also responsible for the enhanced permeability and retention effect, which causes concentration of the particles in target tumor tissue. However, SPIONs with a particle size smaller than $2 \mathrm{~nm}$ are not suitable for medical use. This is due to the increased potential of particles in this size range to diffuse through cell membranes, damaging intracellular organelles and thus exhibiting potentially toxic effects. Therefore, control of particle size during preparation of SPIONs is an important concern.

The techniques most commonly employed for measuring the particle size of SPIONs are transmission electron microscopy, dynamic light scattering, and the Scherrer method using $\mathrm{x}$-ray diffractograms. Because only a small number of the particles prepared are of the desired size, it becomes necessary to carry out fractionation of magnetic fluids. Currently applied techniques are centrifugation, size exclusion chromatography, and field flow fractionation. ${ }^{17-19}$ While the first two techniques separate particles on the basis of their density or size, the latter technique utilizes the magnetic properties of SPIONs for their efficient fractionation.

\section{Surface properties}

The surface charge of nanoparticles gives an indication of their colloidal stability. Nanoparticles having high positive and negative zeta potential show dispersion stability and as a result do not agglomerate on storage. Charge also determines the distribution of these particles in the body and is an important parameter affecting internalization of nanoparticles in their target cells. In one study, it has been reported that uncoated and pullulan-coated SPIONs are internalized into cells by different mechanisms, demonstrating surface-dependent particle endocytosis behavior. ${ }^{20}$

SPIONs having a positive charge are better internalized by human breast cancer cells than are negatively charged particles. However, intake of these nanoparticles also depends upon cell type. ${ }^{2}$ Particles with a hydrophobic surface are easily adsorbed at the protein surface (opsonization) and are engulfed by circulating macrophages, resulting in their clearance from plasma. ${ }^{21}$ Therefore, they show a low circulation time. However, particles that are surface-engineered with hydrophilic polymers like 
polyethylene glycol (stealth particles) containing, eg, hydroxyl or amino functional groups, are able to evade engulfment by the reticuloendothelial cells or circulating macrophages, thus having better therapeutic efficacy due to increased residence time in the blood..$^{22}$ Surface-engineering of magnetic nanoparticles with different functional groups imparts different surface characteristics, making them suitable for a wide variety of biomedical and other industrial applications. Coating the surface of SPIONs with different polymers will be discussed in the following sections.

As the size of iron oxide particles reduces into the nanorange, iron ions on the surface of nanoparticles play an important role in determining the magnetic properties of these particles. The oxidation state of the iron ion on the surface of the nanoparticle is sensitive to its surrounding environment, particularly to surfactant exposure. Analysis of the oxidation state of iron ions on the surface of nanoparticles can help in identifying their structure and chemical environment. It has been reported that the oxidation state of the iron ion can have a potential effect on the morphology of nanoparticles prepared. For instance, iron ions in the trivalent state $(+3)$ favor formation of spherical nanoparticles, whereas metal ions in the divalent state (+2) favor formation of nanorods. ${ }^{23}$ The primary objective of research at present is the preparation of uniform and stable SPIONs by controlled synthesis and coating processes. The synthetic route selected not only determines the physical features of SPIONs, but also has a profound effect on their crystallochemical characteristics. ${ }^{24}$

\section{Core fabrication}

Nucleation and crystal growth are the two fundamental steps in preparation of crystals from solution. Taking into consideration the classical model of crystallization proposed by LaMer and Dinegar, monodispersed nanoparticles can be produced by a single short burst of nucleation, which occurs when a solution reaches its critical supersaturation concentration..$^{25}$ Nuclei thus obtained then grow as a result of diffusion of solute particles from the solution onto the surface of the nuclei, until a suitable size is reached. For achieving monodispersity, care must be taken to ensure that nucleation does not occur during the crystal growth phase. Multiple nucleations can also result in formation of uniformly dispersed nanoparticles. This occurs as a result of Ostwald ripening, a self-reforming process whereby small nuclei crystals formed get redissolved and deposit onto larger nuclei, forming large uniform crystals. ${ }^{26}$ Aggregation of smaller units may also result in uniform-sized nanoparticles. ${ }^{27}$
The most commonly used methods for preparation of uniform iron-based nanoparticles in solution are coprecipitation and microemulsion. ${ }^{28}$ Preparation of SPIONs utilizing the coprecipitation method involves two approaches, ie, partial oxidation of ferrous hydroxide suspension by different oxidizing agents such as nitrates, as explored by Sugimoto et al, and addition of base to an aqueous solution containing a mixture of ferrous $\left(\mathrm{Fe}^{2+}\right)$ and ferric $\left(\mathrm{Fe}^{3+}\right)$ ions with 1:2 stoichiometry in an oxygen-free environment. ${ }^{29}$ Massart et al prepared SPIONs utilizing the second approach and obtained a black precipitate of spherical magnetic nanoparticles in the size range of $<20 \mathrm{~nm} .{ }^{30}$ On the other hand, particles obtained using the method reported by Sugimoto et al were larger, ranging from $30 \mathrm{~nm}$ to $200 \mathrm{~nm}$. The size of magnetic nanoparticles prepared by the coprecipitation method largely depends upon the $\mathrm{pH}$ and ionic strength of the precipitating solution. It has been demonstrated that as the $\mathrm{pH}$ and ionic strength of the medium increases, the size of the particles decreases. ${ }^{24}$ These parameters not only affect the size of the nanoparticles formed, but also determine the electrostatic potential on the surface of these nanoparticles, which is indicative of their dispersion stability.

Smaller and more uniform particles can be synthesized using the microemulsion approach. Water-in-oil (w/o) microemulsions (ie, reverse micelle solutions) are transparent, isotropic, and thermodynamically stable liquids. In these systems, the aqueous phase is dispersed as microdroplets in the continuous oil phase, ie, entrapped within the micellar assembly of stabilizing surfactants. ${ }^{28}$ The main advantage of utilizing this approach is that these microdroplets serve as nanoreactors, providing a confined space which limits growth and agglomeration of nanoparticles during their synthesis, thus regulating their size and surface properties. Using this method, iron precursors like ferrous chloride and ferric chloride are precipitated as oxides in the aqueous core. Iron precursors in the organic phase remain unreactive. By controlling the size of the microdroplets, particles in the desired size range can be obtained. A novel nanocomposite consisting of nanometric cores of silver embedded in a matrix of $\gamma-\mathrm{Fe}_{2} \mathrm{O}_{3}$ was prepared by sequential reaction of different mixtures of reverse micelles. ${ }^{31}$

An emerging method for preparation of uniform nanoparticles is the polyol technique, whereby fine metallic particles can be made by reduction of their dissolved metallic salts and direct metal precipitation from solution containing a polyol. Iron particles around $100 \mathrm{~nm}$ prepared by this process have been reported. High temperature decomposition of iron precursors in the presence of suitable surfactants results in 
synthesis of uniform magnetic nanoparticles with a desirable size range and surface properties. Sun et al reported synthesis of monodispersed magnetic nanoparticles sized $3 \mathrm{~nm}$ to $20 \mathrm{~nm}$ by thermal degradation of iron (III) acetylacetonate in phenyl ether in the presence of alcohol, oleic acid, and oleylamine at $265^{\circ} \mathrm{C} .{ }^{32}$ Use of dendrimers as templating hosts for synthesis of magnetic nanoparticles has drawn considerable attention. This is because of the fact that by properly selecting the appropriate dendrimer host, biocompatible SPIONs suitable for in vivo application can be made via a single-step process. ${ }^{33}$ High-energy ultrasound waves can also be utilized for the synthesis of magnetite and maghemite nanoparticles. These high-energy sound waves create acoustic cavitations, ie, formation, growth, and implosive collapse of empty cavities, resulting in transient localized hot spots with a temperature of about $5000 \mathrm{~K} \cdot{ }^{34,35}$ Formation of these cavities sends out shock waves, leading to particle size reduction with concomitant formation of magnetite nanoparticles. However, large-scale synthesis of magnetic nanoparticles utilizing this approach is not very feasible. Magnetic nanoparticles have also been synthesized by electrochemical deposition of metal on a cathode, produced by reduction of metal ions dissolved from the anode. ${ }^{24}$

Spray and laser pyrolysis are two further emerging approaches for preparation of uniform magnetic nanoparticles, with great commercial scale-up potential. In spray pyrolysis, a solution of $\mathrm{Fe}^{3+}$ salt and reducing agents is sprayed through a series of reactors where aerosol droplets undergo evaporation of solvents with solute condensation within the droplets. This is followed by drying and thermolysis of the precipitated product at high temperature, resulting in microporous solids finally sintering to form dense particles. ${ }^{24}$ Laser pyrolysis involves heating a flowing mixture of gases with a continuous wave carbon dioxide laser, initiating and sustaining a chemical reaction. Homogenous nucleation of particles results when a critical concentration of nuclei is reached within the reaction zone above a certain pressure and laser power. Usually, iron pentacarbonyl is used as a precursor for synthesis of $\gamma-\mathrm{Fe}_{2} \mathrm{O}_{3}$ nanoparticles by the laser pyrolysis method. ${ }^{24,36}$

Magnetotactic bacteria, a group of Gram-negative prokaryotes, have demonstrated an ability to synthesize fine iron oxide nanoparticles in the size range of 50-100 nm. These bacterial magnetic nanoparticles are covered with phospholipid layers, making them biocompatible and hence useful for a variety of bioapplications. ${ }^{37,38}$ Researchers have also used a variety of natural protein components, such as ferritin, which serve as nanoshells consisting of a central core within which iron oxide nanoparticles $6-8 \mathrm{~nm}$ in size can be synthesized. ${ }^{39,40}$ Table 1 summarizes the various methodologies, along with their advantages and disadvantages, used for preparation of SPIONs.

\section{Coating}

The next step after fabrication of SPION cores is their coating. Coating with suitable polymers endows some important characteristics to these nanoparticles that are essential for their use as drug delivery vehicles. Coating of SPIONs is essential because: it reduces the aggregation tendency of the uncoated particles, thus improving their dispersibility and colloidal stability; protects their surface from oxidation; provides a surface for conjugation of drug molecules and targeting ligands; increases the blood circulation time by avoiding clearance by the reticuloendothelial system; makes the particles biocompatible and minimizes nonspecific interactions, thus reducing toxicity; and increases their internalization efficiency by target cells. The presence of amino groups on the coating shell of amino-polyvinyl alcohol-functionalized SPIONs increases their uptake by human melanoma cells, as reported by Petri-Fink et al. ${ }^{41}$ Table 2 lists the most commonly used coating materials for SPIONs.

SPIONs can be coated either during their synthesis or can undergo adsorption after synthesis. ${ }^{21}$ Both methods have been reported to produce particles with a uniform coating. However, coating of SPIONs with nonmagnetic polymers like polysaccharides leads to a decrease in saturation magnetization as compared with uncoated SPIONs. Amstad et al have reported a decrease in saturation magnetization of mPEG(550)-gallol-stabilized SPIONs as compared with bare particles, from $58 \mathrm{emu} \mathrm{g}_{\mathrm{Fe}}{ }^{-1}$ to $50 \mathrm{emu}_{\mathrm{Fe}}{ }^{-1}$, as measured by a superconducting quantum interference device. ${ }^{6}$ A large decrease in saturation magnetization is undesirable because it will result in failure to attain an effective concentration of SPIONs at the target site on application of the external magnetic field. The SPIONs should be coated in such a manner that the coating not only imparts favorable characteristics but also preserves the desirable properties of uncoated SPIONs.

\section{Drug loading}

The primary requirement is that the drug should be loaded in such a manner that its functionality is not compromised. Moreover, these drug-loaded nanoparticles should also release the drug at the appropriate site and at a desired rate. Drug loading can be achieved either by conjugating the therapeutic molecules on the surface of SPIONs or by 


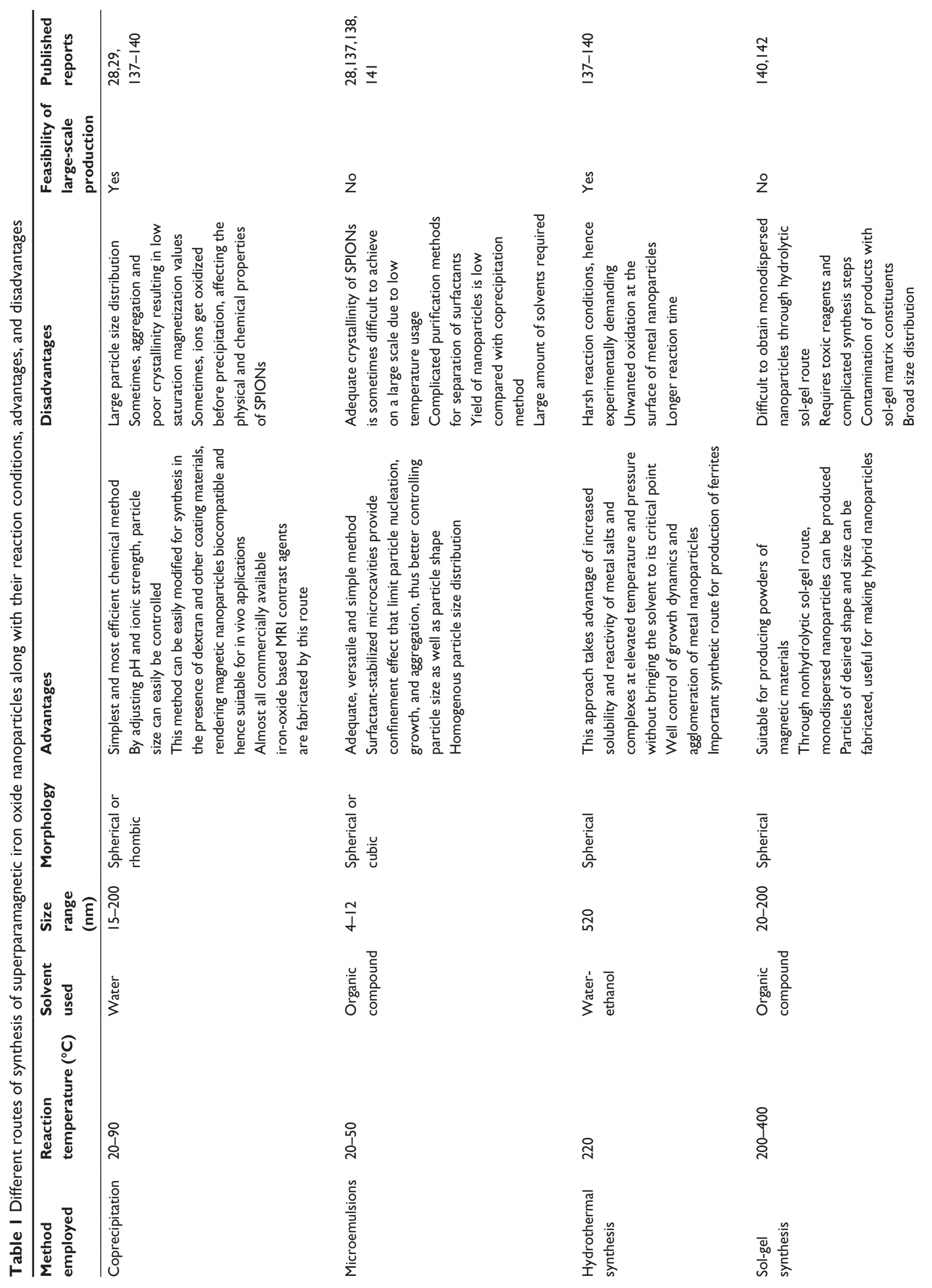




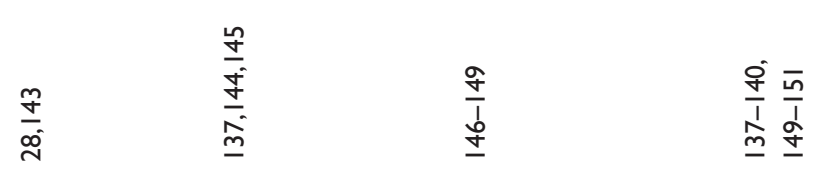

$\frac{\frac{N}{n}}{\frac{N}{\infty}}$

z

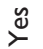

$\stackrel{\check{0}}{\tau}$

$\stackrel{y}{\sim}$
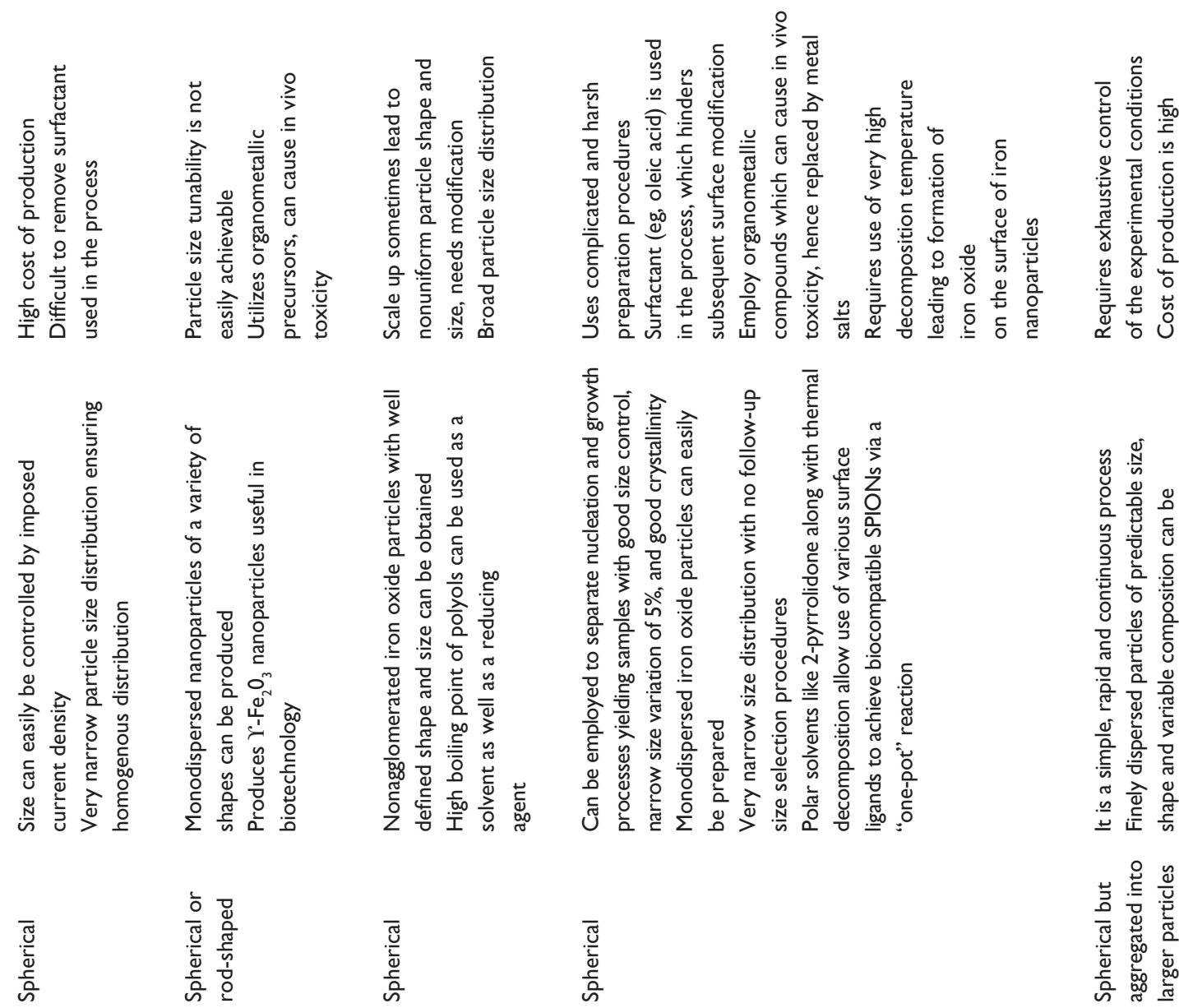

$\frac{\sqrt{\frac{\pi}{2}}}{\frac{\pi}{0}}$

$\frac{.0}{\frac{0}{0}}$
$\frac{\pi}{0}$
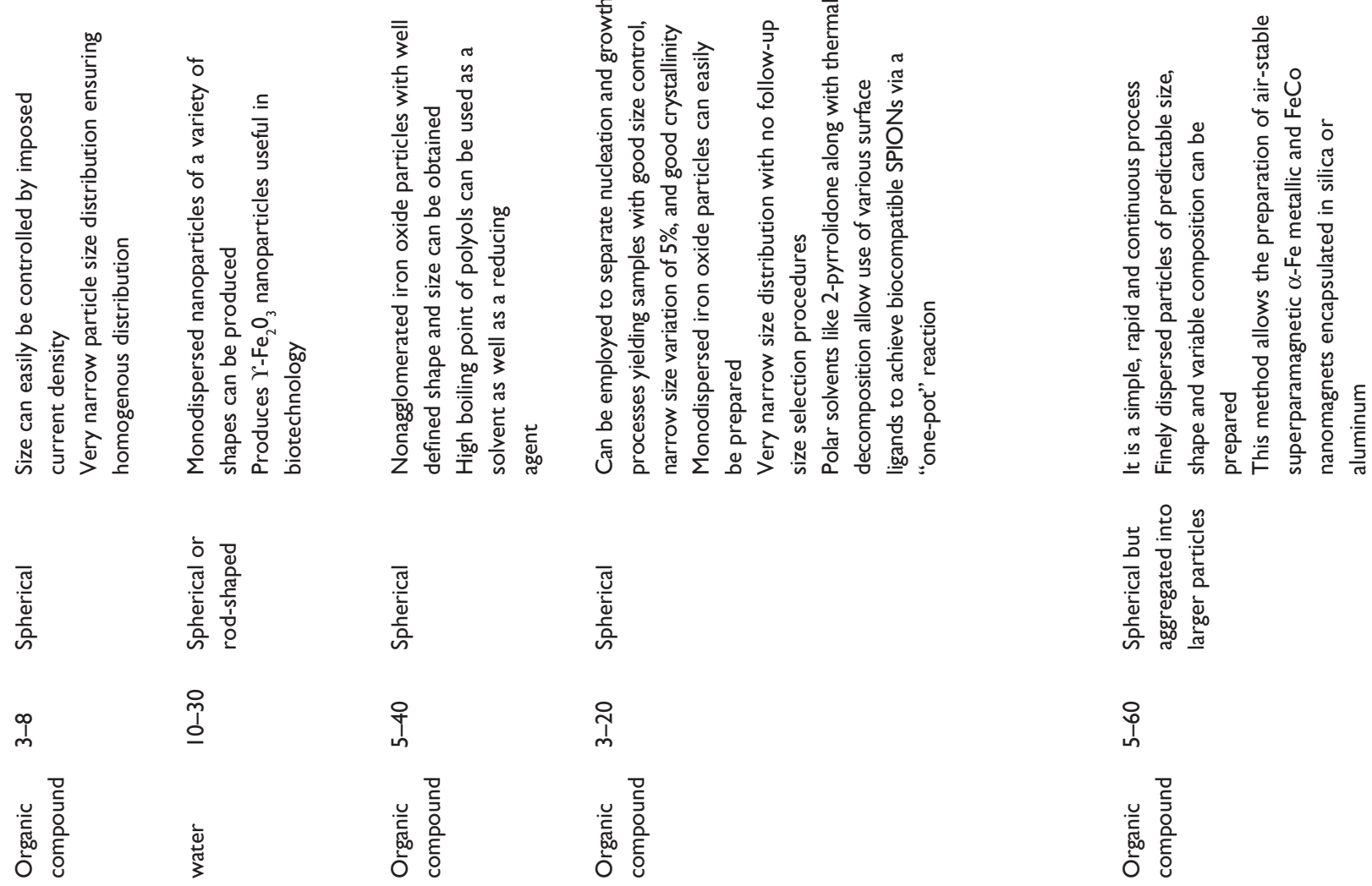

요

운

오ํ

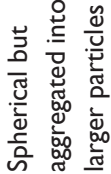

두

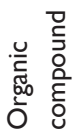

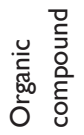

옹

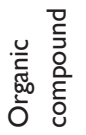

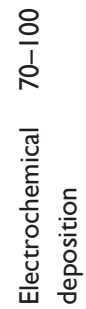

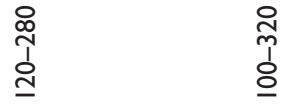

융

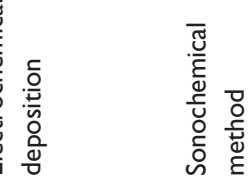

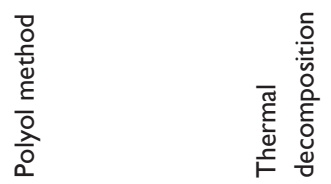

$\frac{n}{n}$
$\frac{\pi}{0}$
$\frac{1}{2}$
$\frac{0}{0}$
ลे 


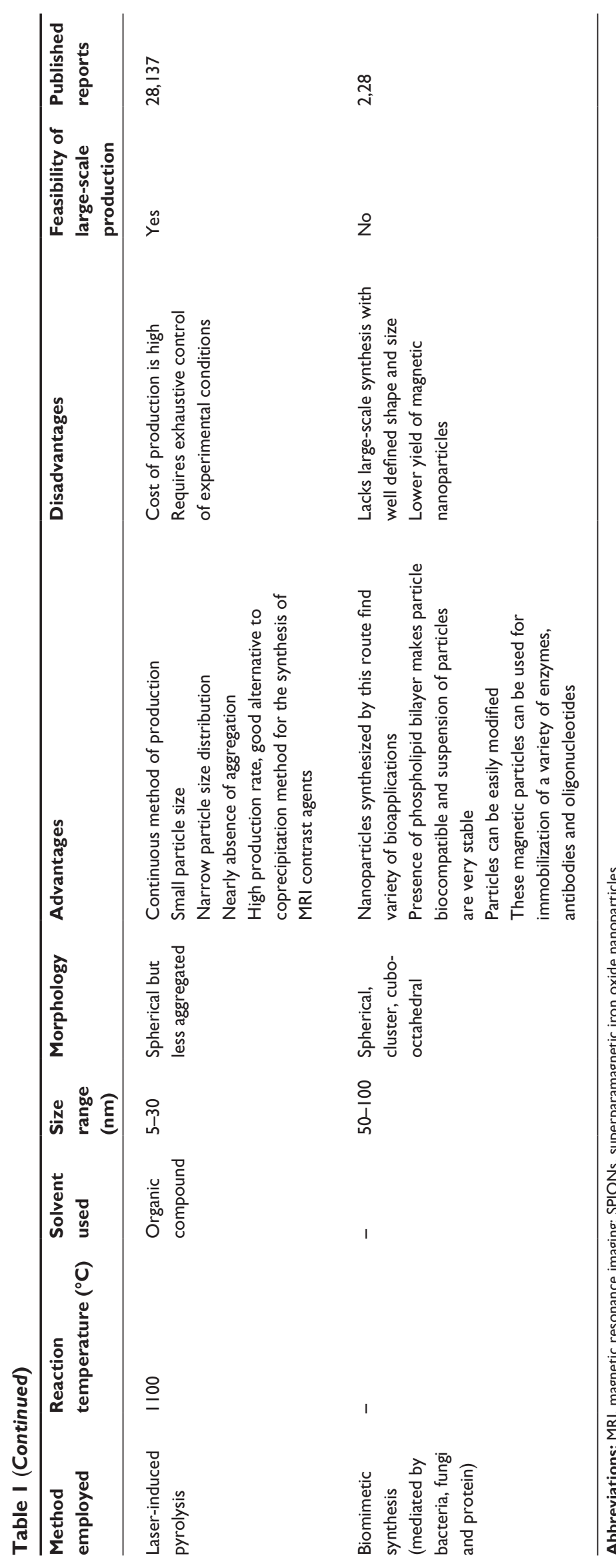




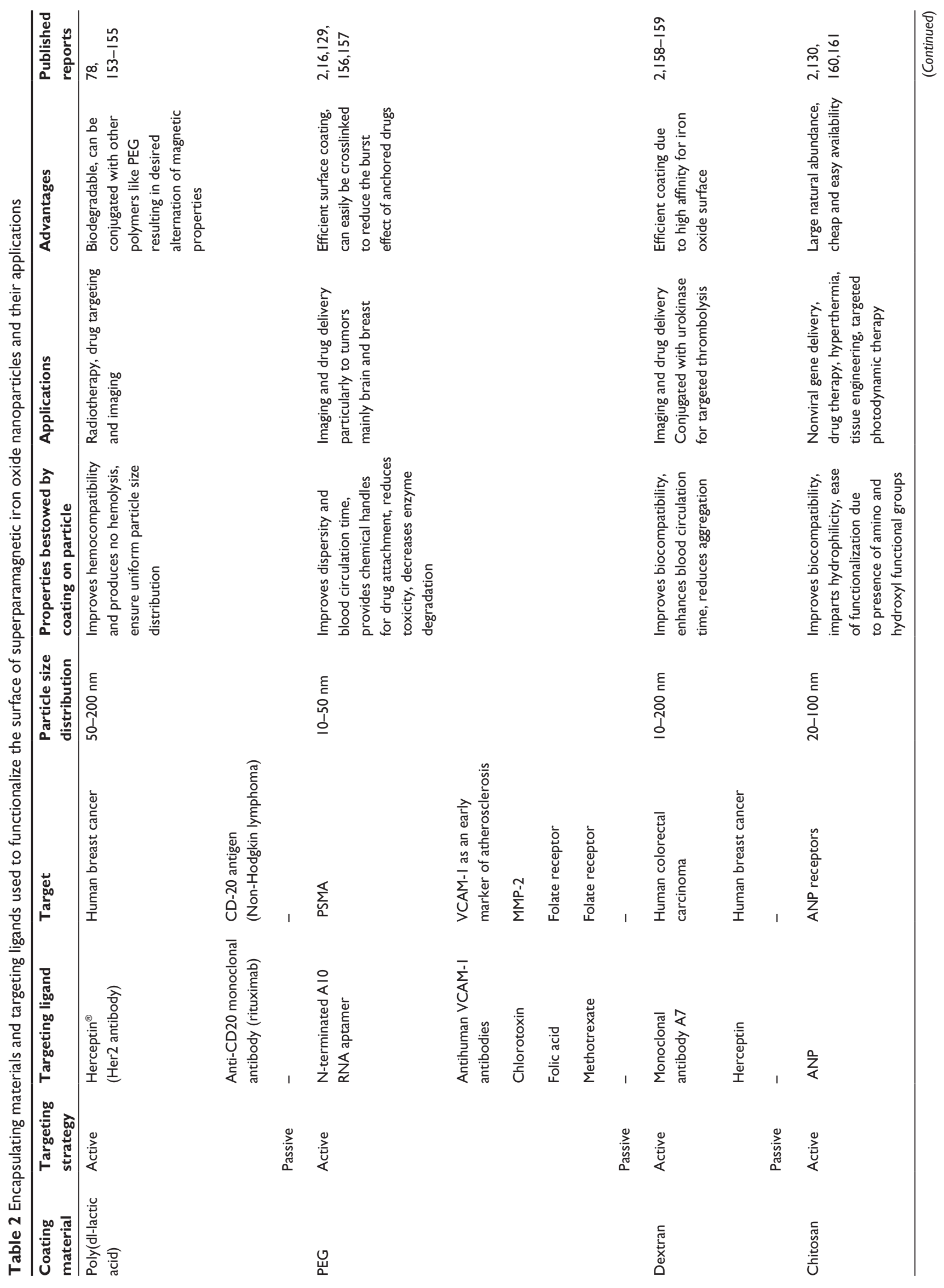




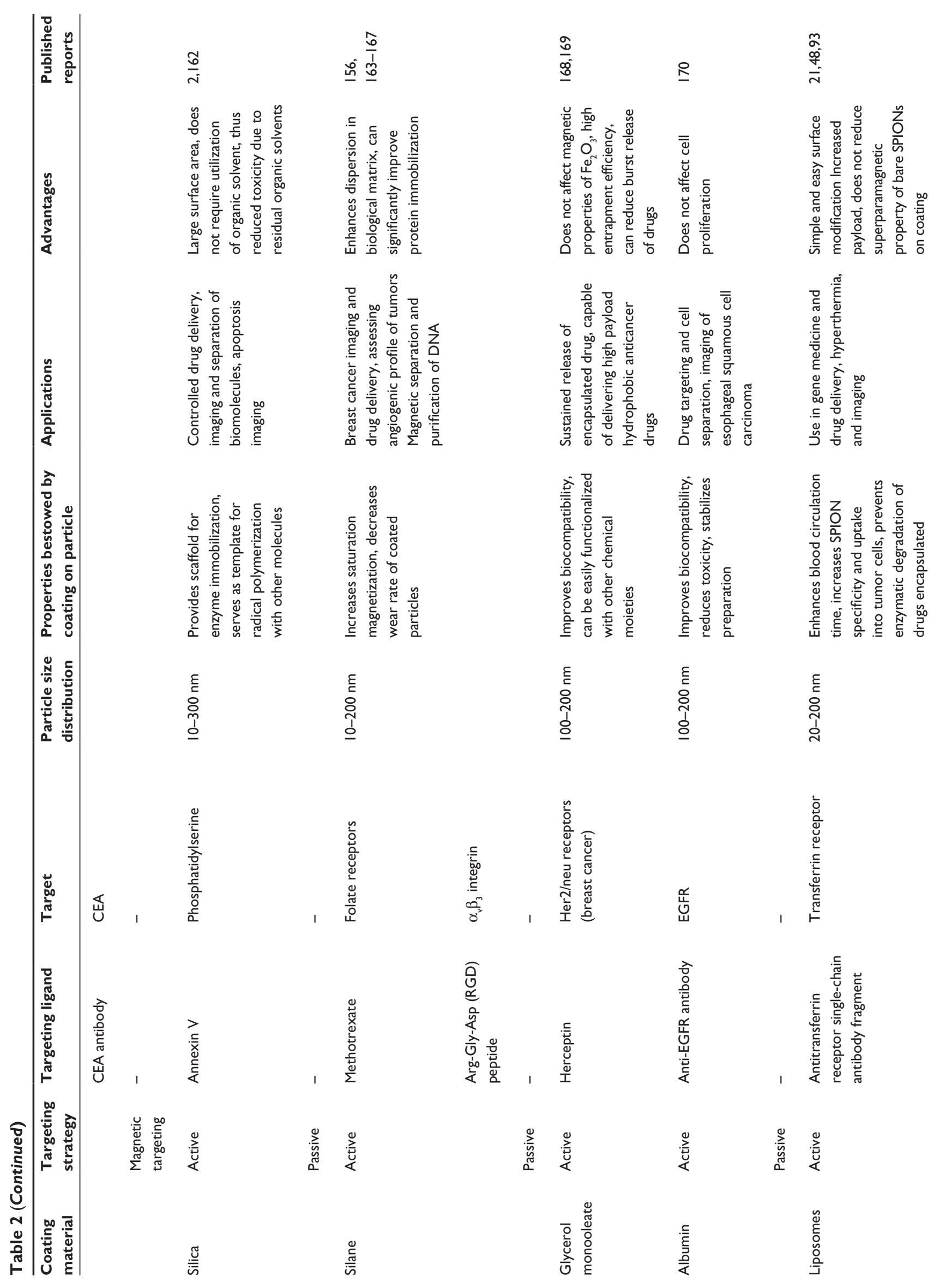




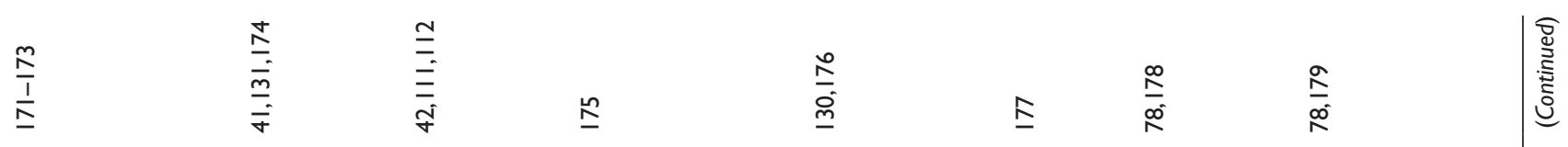

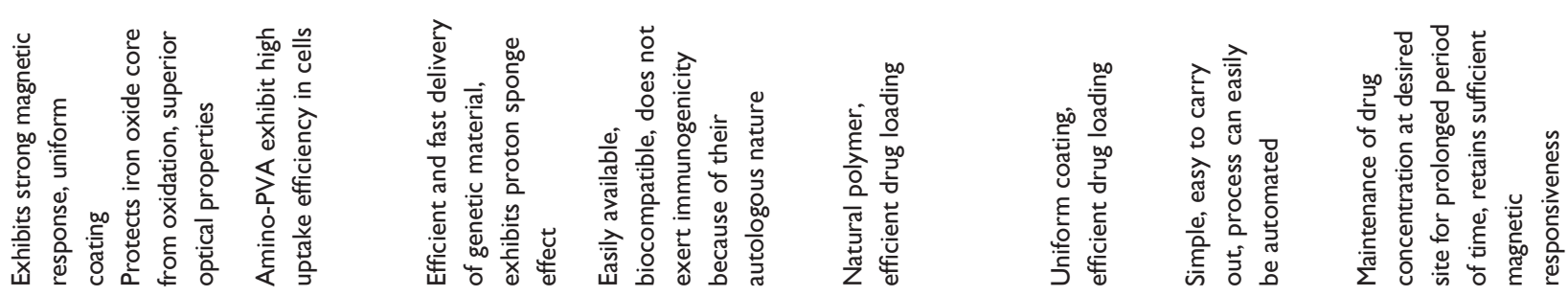

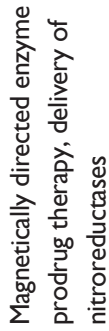

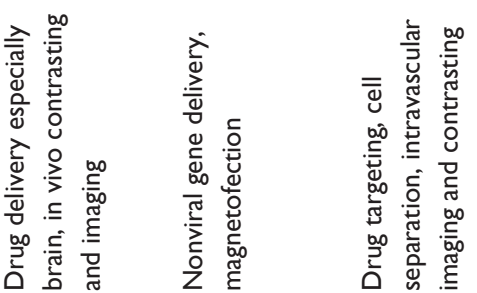

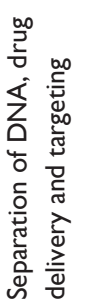

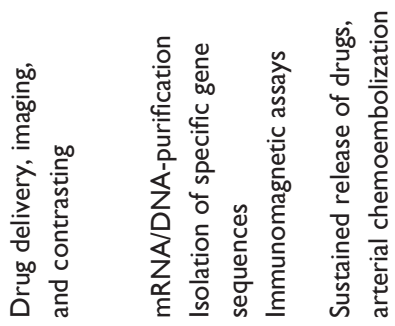

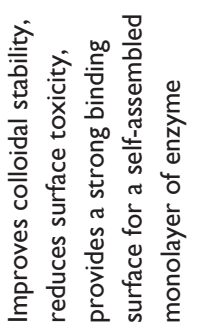

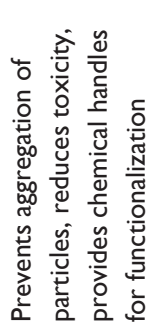

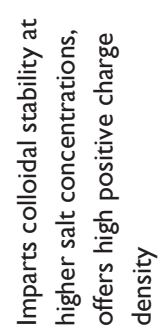
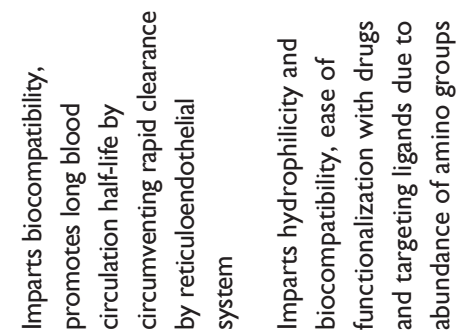

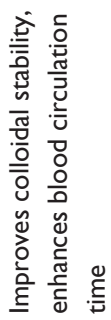

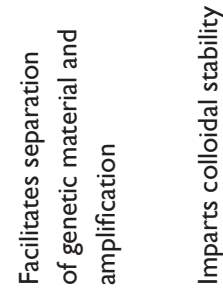

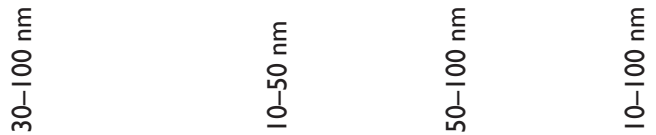

$\frac{\varepsilon}{\frac{\varepsilon}{0}}$

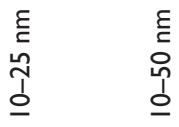

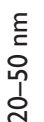
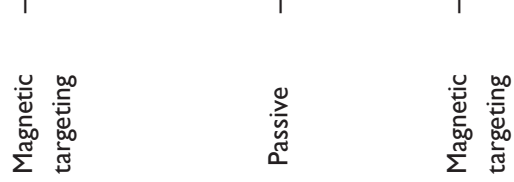

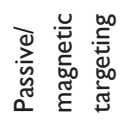

$\sum_{\substack{y\\}}^{\infty}$

$\sum_{\bar{y}}$

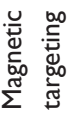

응

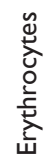

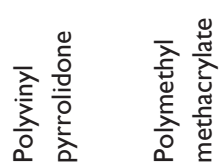

总 


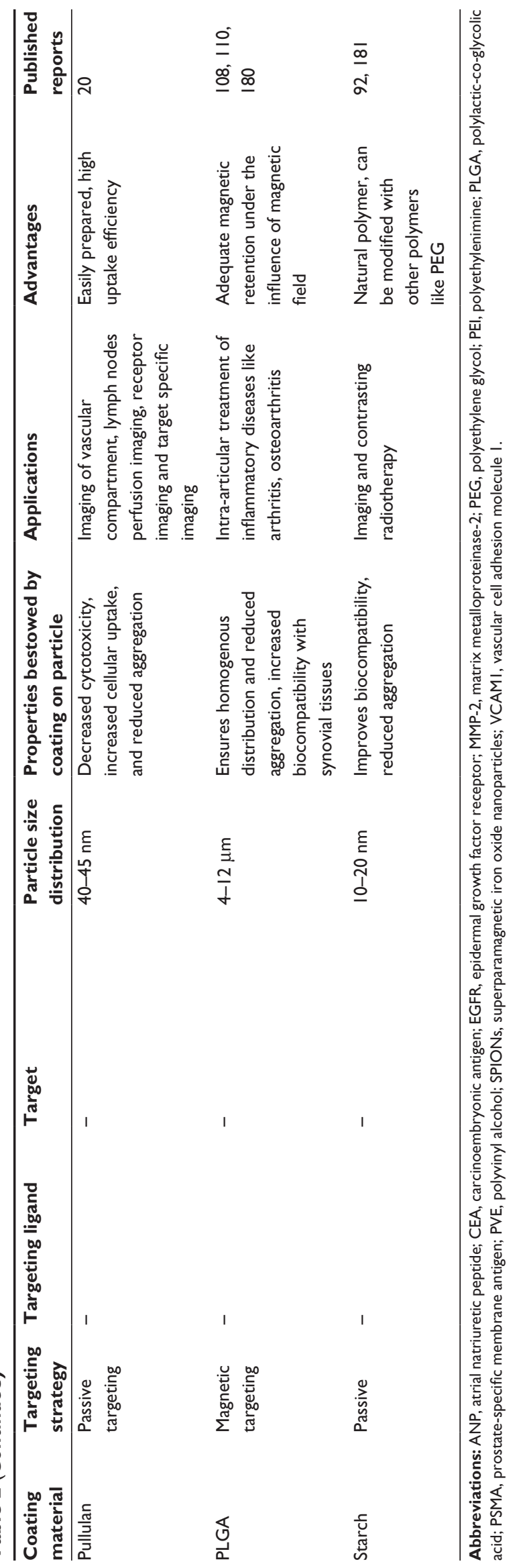

coencapsulating drug molecules along with magnetic particles within the coating material envelope.

A number of approaches have been developed for conjugation of therapeutic agents or targeting ligands on the surface of these nanoparticles. They can be grouped under two categories, ie, conjugation by means of cleavable covalent linkages and by means of physical interactions. Covalent linkage strategies involve linkage of the therapeutic agent or targeting molecules directly with, eg, amino or hydroxyl functional groups present on the surface of polymer-coated SPIONs. Alternatively, linker groups such as iodoacetyls, maleimides, and the bifunctional linker, pyridyl disulfide, may be used to attach the drug to the particle. This approach not only leads to enhanced loading capacity, but also results in more specific linkages, protecting the drug's functionality and hence efficacy. Another advantage of using linkers is that this method involves milder reactive conditions for attachment, and hence is suitable for drugs like therapeutic peptides and proteins, which are prone to oxidative degradation. ${ }^{21}$

Physical interactions such as electrostatic interactions, hydrophobic/hydrophilic interactions, and affinity interactions can also lead to coupling of drug molecules on the surfaces of SPIONs. SPIONs coated with polyethylenimine (PEI), a cationic polymer, interact electrostatically with negatively charged DNA, demonstrating their applicability as transfection agents. ${ }^{42}$ Similarly, dextran-coated SPIONs functionalized with negatively charged functional groups can couple with peptide oligomers via electrostatic interactions. ${ }^{43}$ Because of hydrophobic interactions, lipophilic drugs can easily be attached to SPIONs covered with hydrophobic polymers, from where the drug can be released when the coating degrades. Affinity interactions, such as streptavidinbiotin interactions, can also be utilized for bioconjugation of targeting agents or drugs with SPIONs. Unlike electrostatic and hydrophobic interactions, affinity interactions offer the most stable noncovalent linkages, which are relatively unaffected by environmental conditions, such as changes in $\mathrm{pH}$ and ionic strength of the medium.

However, drug delivery by conjugating the drugs onto the surface of SPIONs suffers from some disadvantages. Low entrapment efficiency of drug molecules is one of the major drawbacks of delivering the drug by coating the surface of SPIONs because only a limited amount of drug can be conjugated in this way. Other disadvantages include highly stable linkages as a result of covalent bonding between drug molecules and the surface of SPIONs, leading to failure to release the drug molecule at the target site. Sometimes, a catalyst such as copper used during covalent linking of a 
drug to the SPION surface may cause in vivo toxicity if it is not purified properly. It has also been shown that it may be difficult to control the orientation of binding ligands when attaching them to the surface of magnetic nanoparticles. This has been observed, particularly in cases where SPIONs decorated with carboxylic acid groups bind with ligands with multiple amine groups, often leading to inactivation of ligands. ${ }^{21}$

Loading of drug molecules along with iron oxide nanoparticles within the coating material represents another approach of delivering a drug to the target site. This approach provides attractive solutions to problems such as low entrapment efficiency and stability. Magnetoliposomes represent a new class of nanocomposites which not only ensures high entrapment efficiency but also better stability and magnetic properties. ${ }^{44}$ Magnetoliposomes are nanosized, spherical vesicles consisting of magnetic nanoparticles in a shell composed of a phospholipid bilayer. These magnetoliposomes retain hydrophobic regions that can be used for drug encapsulation. Loading SPIONs with pharmaceuticals within the phospholipid envelope offers several advantages. Firstly, liposomes containing magnetic particles provide simple and easy surface modifications enabling their targeting to a specific tissue. Secondly, magnetoliposomes containing high amounts of SPIONs due to increased entrapment efficiency provide optimum magnetic responsiveness and their nanosize enables exploitation of the enhanced permeability and retention effect for tumor targeting. In addition, a larger amount of both hydrophilic as well as hydrophobic drug can be loaded within the liposomal structure along with SPIONs. Thirdly, encapsulation of SPIONs within liposomes further improves the biocompatibility of SPIONs. Fourthly, the liposomal barrier protects encapsulated pharmaceuticals from the degradative effects of the surrounding environment. ${ }^{45}$ SPIONs can be loaded within the liposomes in two ways, ie, by incubating previously prepared liposomes and SPIONs under the influence of an external force resulting in localization of SPIONs within the hydrophilic core of liposomes, ${ }^{46,47}$ or by directly precipitating the SPIONs within the hydrophilic core of liposomes, yielding highly uniform nanoparticles with sizes around $15 \mathrm{~nm} .{ }^{48}$ However, during coating, agglomerates of SPIONs sometimes get coated instead of discrete SPION cores being coated within a phospholipid shell. This results in poor magnetic and physicochemical properties. Exposing magnetoliposomes to a strong permanent magnetic field over the target tissue leads to alignment of magnetic particles

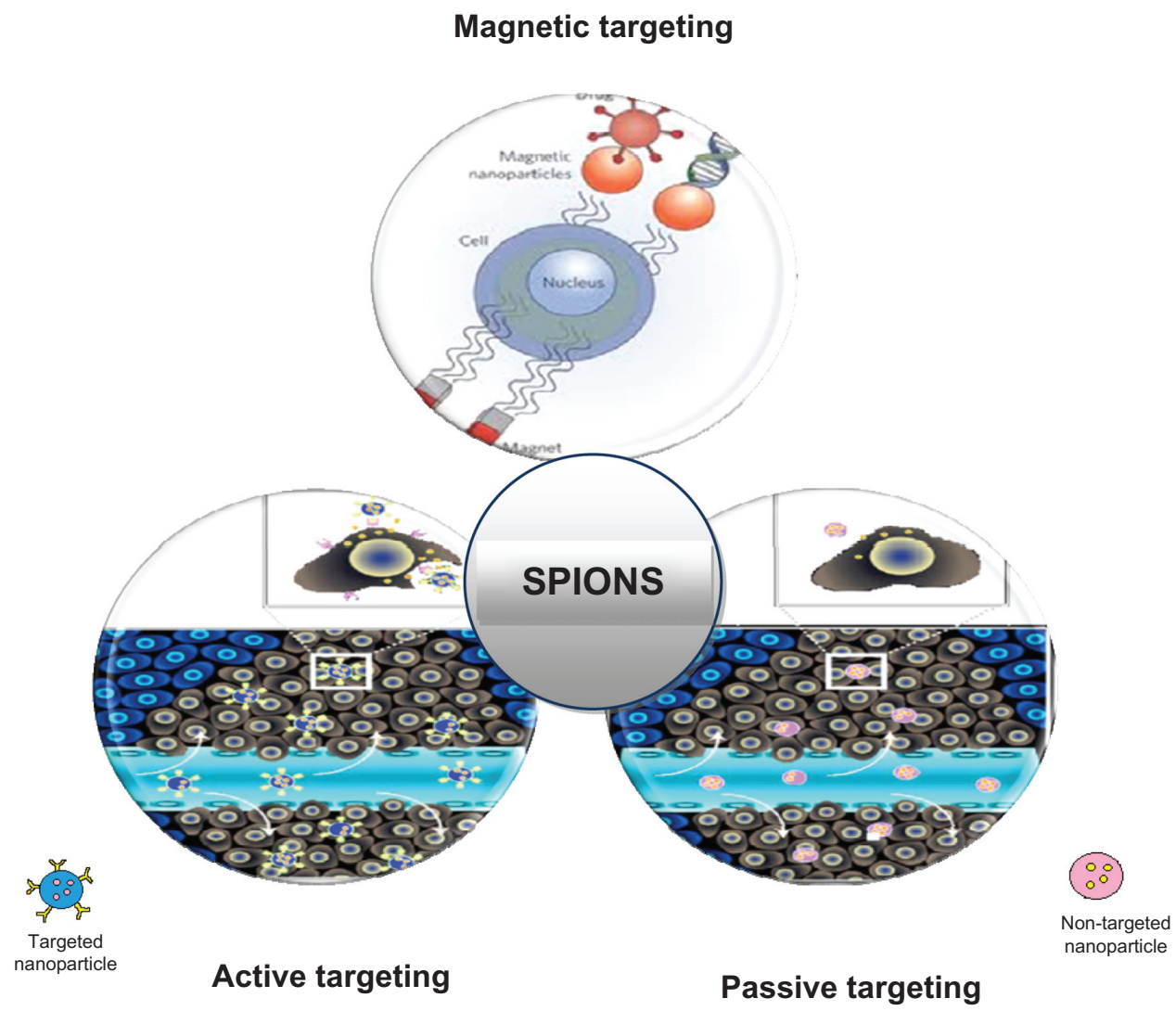

Figure 2 Superparamagnetic iron oxide nanoparticle targeting approaches. ${ }^{2}$ 
within the bilayer, causing magnetoliposomes to aggregate, fuse, and release the drug only at the target site.

Magnetodendrimers represent another class of nanocomposites which are well suited to imaging of cell trafficking and migration using MRI. ${ }^{49-51}$ Carboxylated polyamidoamine dendrimers are commonly used to coat and stabilize iron oxide nanoparticle suspensions. ${ }^{33}$ In general, at an elevated temperature and $\mathrm{pH}$ in the presence of dendrimers, oxidation of Fe(II) yields highly stable and soluble SPIONs with dendrimers. ${ }^{33}$ Lamanna et al developed dendronized iron oxide nanoparticles for multimodal imaging. SPIONs coated with dendrimers having a hydrodynamic size less than $100 \mathrm{~nm}$ and displaying either carboxylate or ammonium groups at the periphery provide a unique opportunity for labeling with a fluorescent dye. Magnetic resonance and fluorescence imaging have been demonstrated to be simultaneously possible. ${ }^{52}$

\section{SPION targeting approaches}

SPIONs can be properly engineered to reach their target tissue with minimum nonspecific cellular interactions. Targeting strategies can be grouped into three classes as shown in Figure 2. Passive targeting takes advantage of the innate size of the nanoparticles as well as the unique characteristics provided by the tumor microenvironment. ${ }^{53}$ Tumor cells exhibit leaky vasculature due to incomplete angiogenesis. ${ }^{53}$ Nanoparticles enter tumor tissue through these pores, and due to the poor lymphatic drainage system of cancerous tissues are retained for longer periods of time than normal cells. This is also known as the enhanced permeability and retention effect, discovered by Matsumura and Maeda. ${ }^{54,55}$ Thus, particle size in the nanorange itself provides targeted delivery, without any modification. The enhanced permeability and retention effect is considered to be the "gold standard" for developing new anticancer agents. ${ }^{56}$

Active targeting involves targeting ligands which are coupled at the surface of magnetic nanoparticles to interact with receptors that are overexpressed at their target sites. Such particles accumulate in larger quantities in target cells due to "homing" of these ligands onto the receptors and subsequent ease of internalization. Various active targeting agents engineered and attached to the SPION surface not only ensure specific target binding but also minimize the dose required and nonspecific cellular interactions. Commonly used targeting ligands are shown in Table 2.

Magnetic focusing uses external magnets to create a suitable magnetic field gradient over the targeted area and ensure significant accumulation of drug-loaded SPIONs. ${ }^{57}$ The strength of the applied magnetic field can be altered to modulate release of the drug in the desired fashion, resulting in maximum therapeutic benefits. A permanent $\mathrm{NdFeB}$ magnet is generally used for magnetic targeting of SPIONs. Mondelak et al increased the permeability of dextran-encapsulated SPIONs over an artificial three-layered membrane on application of an external magnetic field of 0.410 Tesla. ${ }^{58}$ Kumar et al synthesized magnetic nanoparticles coupled with plasmid DNA-expressing enhanced green fluorescent protein and coated with chitosan. The particles were successfully directed to the heart and kidney via an external magnetic field when injected into the tail vein of mice. The results demonstrated that application of an external magnetic field is sufficient to target a drug to its specific site of action, excluding the need to develop functionalized nanoparticles. ${ }^{59}$ In another study, Lamkowsky et al demonstrated time-dependent, temperaturedependent, and concentration-dependent accumulation of dimercaptosuccinate-coated iron nanoparticles in cultured brain astrocytes. The accumulation of iron oxide nanoparticles was proportionally increased with an increase in the applied magnetic field strength, increasing the cell-specific iron content from an initial $10 \mathrm{nmol} / \mathrm{mg}$ of protein within 4 hours of incubation at $37^{\circ} \mathrm{C}$ to up to $12,000 \mathrm{nmol} / \mathrm{mg}$ of protein. The results suggested that application of an external magnetic field enhanced both binding of iron nanoparticles to cell membranes as well as their internalization in cultured astrocytes, demonstrating the utility of SPIONs as potential diagnostic and drug delivery vehicles for imaging and treatment of neurodegenerative diseases. ${ }^{60}$ Prijic et al studied the potential increase in cellular internalization of SPIONs by exposure of different cells to an external magnetic field generated by different permanent magnets. They found that exposure to neodymium-iron-boron magnets significantly increased the cellular uptake of SPIONs, predominantly into malignant cells. Accumulation of SPIONs within malignant cells was found to be dependent on duration of exposure to the external magnetic field. ${ }^{61}$

\section{Absorption, distribution, metabolism, and excretion of SPIONs}

For a chemical to be called a drug, it ought to have optimal pharmacokinetic properties as well as be formulated into an appropriate delivery system with desirable pharmacokinetic parameters. If these magnetic nanoparticles are intended to translate from benchtop research to clinical settings, detailed investigation of their pharmacokinetics, ie, their absorption and internalization mechanisms in different cells, their 
biodistribution, and metabolic fate, as well as their elimination from biological systems, is of prime importance.

\section{Internalization and biodistribution in different cells}

The literature reports a wide variety of processes for the internalization of SPIONs by different cells. Given intravenously, these magnetic particles are predominantly taken up by phagocytes in the reticuloendothelial systems of the liver, spleen, and lymph tissue. ${ }^{62,63}$ In a study conducted by Gu et al, biocompatible, dimercaptosuccinic acid-coated SPIONs were internalized into macrophage-like RAW264.7 cells utilizing multiple endocytic uptake pathways, such as clathrindependent endocytosis, caveolae-dependent endocytosis, and macropinocytosis or phagocytosis. Marked inhibition of SPION internalization was observed when RAW264.7 cells were pretreated with chlorpromazine (inhibits clathrindependent endocytosis by promoting loss of clathrin and the AP2 adapter complex from the cell surface), multilayer $\beta$-cyclodextrin (inhibits caveolae-dependent endocytosis by depleting membrane cholesterol), and amiloride (inhibits macropinocytosis by blocking activity of the $\mathrm{Na}^{+} / \mathrm{H}^{+}$ exchanger in the plasma membrane). These results confirmed that several endocytic uptake mechanisms worked cooperatively for uptake of SPIONs by macrophage-like RAW264.7 cells. ${ }^{64}$ However, in another study by Yang et al, ferucarbotran, a clinically approved SPIO-coated carboxydextran with a mean diameter range of 45-60 nm, was found to be internalized in macrophage-like RAW264.7 cells via clathrin-dependent endocytosis. ${ }^{65}$ It seems that there is a correlation between SPION factors (size, surface charge, and surface coating) and endocytotic pathways, that needs to be explored in more detail.

SPIONs administered intravenously have to cross the vascular endothelium, ie, the primary barrier, in order to reach their target site. Hanini et al evaluated the interaction between human endothelial cells and $\gamma-\mathrm{Fe}_{2} \mathrm{O}_{3}$ nanoparticles using confocal microscopy. Human umbilical vein endothelial cells were incubated with FITC-labeled $\gamma-\mathrm{Fe}_{2} \mathrm{O}_{3}$ nanoparticles at a concentration of $10 \mu \mathrm{g} / \mathrm{mL}$. The $\gamma-\mathrm{Fe}_{2} \mathrm{O}_{3}$ nanoparticles were efficiently internalized by the human umbilical vein endothelial cells, with the majority of fluorescence localized within the cytoplasm. These investigators demonstrated that $\gamma-\mathrm{Fe}_{2} \mathrm{O}_{3}$ nanoparticles could penetrate cells without protein-coated vesicles, suggesting a micropinocytotic process. ${ }^{66}$

Wang et al evaluated the pharmacokinetic parameters and tissue distribution of magnetic $\mathrm{Fe}_{3} \mathrm{O}_{4}$ nanoparticles prepared by a chemical coprecipitation method in imprinting control region mice. Using atomic absorption spectrophotometry, they found a wide distribution of SPIONs in various target organs and tissues, including the heart, liver, spleen, lungs, kidney, brain, stomach, small intestine, and bone marrow. However, the concentration of SPIONs was highest in the liver and spleen, thus demonstrating more pronounced curative effects of SPIONs in these organs. ${ }^{67}$

Particle size, surface coating, and surface charge are major determinants of the biodistribution, pharmacokinetics, and possible toxicity of SPIONs. ${ }^{15}$ Tissue distribution is mainly affected by particle size. SPIONs with a particle size smaller than $50 \mathrm{~nm}$ evade opsonization, thus increasing their circulation time and hence are gradually taken up by macrophages in the reticuloendothelial systems of the liver, lymph tissue, spleen, and bone marrow, whereas magnetic particles smaller than $50 \mathrm{~nm}$ are rapidly cleared from the bloodstream by sinusoidal Kupffer cells in the liver. ${ }^{63}$ In addition to particle size, the coating material used on iron oxide particles also determines the rate of hepatic clearance. In general, SPIONs covered with coating materials which hinder access of water to the iron oxide core show slower degradation and hence an increased half-life in blood. ${ }^{68}$ Surface charge, in addition to particle size and the coating material, affects the uptake of SPIONs by different cells. For instance, positively charged particles adhere nonspecifically to cells because the majority of the cell membranes have a net negative charge, whereas strong negative charges on the surface of magnetic particles facilitate their uptake by the liver. ${ }^{68}$ Schlorf et al compared SPIONs with different core materials (magnetite, maghemite), different coatings (none, dextran, carboxydextran, and polystyrene) and different hydrodynamic diameters (20-850 nm) with regard to their internalization mechanisms, release of internalized particles, toxicity, and ability to generate contrast in MRI. For this study, they utilized U118 glioma cells and human umbilical vein endothelial cells exhibiting different phagocytic activity. Noncoated, carboxydextran-coated, and polystyrene-coated nanoparticles with a varying size range $(10-850 \mathrm{~nm})$ showed very nonspecific phagocytic uptake by tumor cells and endothelial cells. The coating and surface charge of the particles were demonstrated to exert a much larger influence on their nonspecific uptake than their size. Dextran-coated particles on the other hand were found to have completely different uptake behavior. The reason for this different uptake behavior was attributed to the dextran coating, making these nanoparticles suitable for specific labeling of molecular targets. ${ }^{69}$ 


\section{Elimination from biological systems}

An ideal drug delivery system, after delivering its payload to the target site, should be completely eliminated from the biological system with minimal harmful effects. Because SPIONs are increasingly being investigated for a variety of biomedical applications, ie, targeted drug delivery, tumor magnetic hyperthermia therapy, and contrast enhancement of MRI, detailed elucidation of their metabolic pathways and clearance mechanisms should be carried out, so as to rule out any potential toxicity associated with their intended use. Given that elimination is a broader term, which includes metabolism as well as excretion, the following section will provide a better understanding of the metabolic as well as clearance pathways of SPIONs in biological systems.

\section{Metabolism}

The uptake, distribution, metabolism, and excretion of dietary iron is highly regulated in biological systems. Specialized mechanisms which govern the body's iron regulation processes are also thought to be involved in handling iron oxide nanoparticles. Few reports are available in the literature elucidating their biotransformation in biological systems. Once internalized, lyzosome-mediated degradation is generally considered to be the main intracellular metabolic mechanism involved in the degradation of SPIONs. ${ }^{70,71}$ In order to evaluate the degradation rate of SPIONs internalized within acidic intracellular components, Arbab et al utilized an in vitro lyzosomal environment containing appropriate and/or specific chelates, such as citrates and phosphates, at an acidic $\mathrm{pH}$. They demonstrated that sodium citrate at $\mathrm{pH} 4.5$ rapidly dissolved ferumoxide, a dextran-coated SPION. In the cellular environment, they found that some of the ferumoxidetransfection agent complex containing endosomes fused with the lyzosomes, resulting in their rapid dissolution at low $\mathrm{pH}$, exposing the iron core to chelates, thus liberating the soluble free Fe(III) into the cytoplasm via divalent cationic transport. ${ }^{70}$ In another study, Gu et al proposed three possible mechanisms for the metabolic fate of SPIONs internalized in RAW264.7 cells, and supported them with the data generated. Firstly, during mitotic division of cells, intracellular SPIONs get distributed to the daughter cells. This mechanism is considered to be the major route of elimination of SPIONs from macrophages. Secondly, internalized iron oxide nanoparticles get degraded at low lyzosomal $\mathrm{pH}$, releasing free $\mathrm{Fe}$ (III) within the intracellular medium. The iron released is stored in the body reserves with the help of iron-regulating proteins, ie, ferritin and hemosiderin. Thirdly, some of the internalized SPIONs may potentially be exocytosed out of
RAW264.7 cells, although direct evidence for this proposed mechanism is lacking. ${ }^{64}$ Levy et al conducted a long-term (3-month) in vivo biotransformation study of $8 \mathrm{~nm}$ SPIONs coated with hydrophilic glucose derivatives following intravenous administration in mice. Using ferromagnetic resonance and superconducting quantum interference device measurements, they supported the view of continuous biotransformation of injected magnetic nanoparticles into iron storage species within intracellular lyzosomes. ${ }^{72}$

\section{Excretion}

The most desirable pathway for SPIONs to be excreted from biological systems is via the kidney, because this route involves minimal intracellular catabolism, reducing the probability of generating reactive oxygen species and hence associated toxicity. Renal excretion represents the safest route of elimination for SPIONs. However, the shape, hydrodynamic size, surface coating, and surface charge of SPIONs play a major role in regulating their renal clearance. It is noteworthy that the coating chemistry in particular has a profound effect on renal clearance of SPIONs. For instance, $55 \%$ of the intravenous dose of SPIONs coated with Pluronics ${ }^{\circledR} /$ oleic acid with a hydrodynamic diameter of $193 \mathrm{~nm}$ was shown to accumulate in the rat liver. ${ }^{73}$ On the other hand, SPIONs with dextran as the coating material have been reported to undergo $18 \%-22 \%$ elimination via the urine and feces over a period of 7 weeks in different animal species. ${ }^{74}$ Some studies even report more rapid clearance of dextran-coated SPIONs (nearly 25\%) in 19 days via the urine and feces. ${ }^{75}$ This difference in clearance rate can be attributed to differential protein corona compositions which in fact are governed by the surface chemistry of these magnetic nanoparticles. For magnetic nanoparticles with a diameter less than $40 \mathrm{~nm}$, the coating material has much more significance than any other physicochemical parameter in determining their biodistribution as well as blood half-life. ${ }^{68}$

Cell type, in addition to physicochemical parameters, also plays an important role in determining the cellular uptake, intracellular metabolism, and toxicity associated with SPIONs. Mahmoudi et al have shown that at the same iron concentrations (above $2.25 \mathrm{mM}$ ), SPIONs with different surface coatings are toxic to human brain cells while completely compatible with human kidney cells. ${ }^{76,77}$

\section{Utility as drug delivery vehicles}

SPIONs have emerged as an attractive alternative for targeted delivery of drugs because of their unique magnetic characteristics. Their role as contrast agents in MRI has 
Table 3 Role of superparamagnetic iron oxide nanoparticles in different areas of magnetic resonance imaging

\begin{tabular}{|c|c|c|}
\hline Focus area & Important remarks & References \\
\hline Molecular imaging & $\begin{array}{l}\text { - Allows sensitive and specific monitoring of key molecular targets } \\
\text { - Allows monitoring of host responses associated with early events in carcinogenesis } \\
\text { - Imaging of cell trafficking/migration, apoptosis detection and imaging of enzyme activities }\end{array}$ & $182-188$ \\
\hline Cardiovascular disease imaging & $\begin{array}{l}\text { - Uptake by macrophages utilized to visualize atheromatous plaques prone arterial sites } \\
\text { - Useful in evaluating the risk of acute ischemic events }\end{array}$ & $62,189-192$ \\
\hline Cancer imaging & $\begin{array}{l}\text { - Utilized in clinical imaging of liver and spleen tumors and metastases through } \\
\text { RES-mediated uptake } \\
\text { - Effective in identification of lymph node metastases, useful in treatment of prostate, } \\
\text { breast, and colon cancer } \\
\text { - Prolonged delineation of brain tumor boundaries and quantify tumor volumes } \\
\text { - Useful in imaging CNS tumor neovasculature and assessing therapeutic } \\
\text { response to antiangiogenic chemotherapeutic agents }\end{array}$ & $62,82,191-197$ \\
\hline Autoimmune disorders imaging & $\begin{array}{l}\text { - Used to visualize macrophage infiltration in brain, assess blood-brain barrier } \\
\text { damage and neurological impairment in chronic relapsing experimental autoimmune } \\
\text { encephalomyelitis, rodent model of human multiple sclerosis } \\
\text { - Used to monitor distinct pattern of macrophage migration in acute disseminated } \\
\text { encephalomyelitis }\end{array}$ & $82,192,198,199$ \\
\hline Central nervous system disease imaging & $\begin{array}{l}\text { - Serve as useful tool for noninvasive anatomic and temporal tracking of stem } \\
\text { cells in CNS trauma and stroke } \\
\text { - Used to monitor disease progression in epilepsy } \\
\text { - Allows MRI visualization of neuroinflammation in vivo } \\
\text { - Allows monitoring of leukocyte trafficking in the brain }\end{array}$ & $82,200-204$ \\
\hline
\end{tabular}

Abbreviations: CNS, central nervous system; MRI, magnetic resonance imaging; RES, reticuloendothelial system.

already been established, particularly for tumor imaging and cardiovascular disease. Moreover, these magnetic nanoparticles are increasingly being investigated for their potential application in the delivery of chemotherapeutic drugs, radionuclides, and anti-inflammatory agents, as well as in gene delivery. ${ }^{21,28,78}$ Magnetic fluid hyperthermia is another approach where SPIONs can be utilized for localized production of heat, resulting in destruction of cancer cells. ${ }^{79}$ SPIONs are also being used in magnetic separation techniques, particularly for immunomagnetic cell separation and purification. ${ }^{78,80}$

The only clinical use for which commercial SPION-based products are available is as MRI contrast agents for the diagnosis of human disease. MRI is one of the most powerful noninvasive imaging techniques used in clinical medicine today. ${ }^{81}$ SPIONs have been used as contrast agents for at least 20 years. Based on their size, SPIONs have been grouped into three categories, ie, standard SPIONs (50-180 nm), ultrasmall SPIONs $(10-50 \mathrm{~nm})$, and very small SPIONs $(<10 \mathrm{~nm}) \cdot{ }^{62}$ Commonly used MRI contrast agents fall into the ultrasmall SPION category and, for the sake of consistency, we will refer to SPIONs in general. SPIONs have emerged as an attractive alternative to gadolinium-based MRI contrast agents, particularly in patients with renal dysfunction, who are at risk of nephrogenic systemic fibrosis. Table 3 lists some of the focus areas of MRI imaging using SPIONs as contrast agents.
Given that the major focus of this review is on highlighting the drug delivery applications of SPIONs, their diagnostic applications are not discussed in detail. Readers who are interested in a more detailed discussion of the role of SPIONs as MRI contrast agents are advised to go through some of the excellent reviews mentioned in the references. ${ }^{21,82-89}$

\section{Role in cancer therapy}

Chemotherapeutic agents are known to exert a plethora of side effects due to their lack of target specificity. SPIONs are capable of ferrying anticancer drugs into malignant cells while sparing healthy cells. This also leads to reduction of the dose required because the drug is delivered directly to target cells. Various anticancer drugs, including paclitaxel, methotrexate, mitoxantrone, and doxorubicin, have been conjugated with magnetic nanoparticles to increase their target specificity. ${ }^{90,91}$ Coating of SPIONs with polymers like aminopolyvinyl alcohol and pullulan have resulted in increased interaction of these nanoparticles with human cancer cells, as well as suppression of cytotoxicity in healthy cells. ${ }^{20,41}$ Polyethylene glycol-modified, cross-linked, and starchcoated iron oxide nanoparticles have been found to enhance magnetic tumor targeting. ${ }^{92}$ Because surface modification or coating can sometimes significantly reduce the superparamagnetic properties of SPIONs, a novel approach of delivering drug-loaded SPIONs by encapsulating them within 
cationic liposomes has been proposed by Yang et al. ${ }^{93}$ These nanocomposites were surface-engineered with antitransferrin receptor single-chain antibody fragments, which delivered the complex to transferrin receptors overexpressed on tumor cells. This nanoimmunoliposome platform technology could specifically and efficiently deliver SPIONs into tumor cells after systemic administration.

SPIONs can also be utilized to overcome multidrug resistance characterized by overexpression of ATP binding cassette transporters that actively pump a large number of hydrophobic chemotherapeutic drugs out of cancer cells. In one experiment, doxorubicin was covalently bound to PEI via $\mathrm{pH}$-sensitive hydrazone linkage and conjugated to an iron oxide nanoparticle coated with amine-terminated polyethylene glycol. The doxorubicin-loaded nanoparticles were taken up by both wild-type and drug-resistant cells, and were retained for longer in the drug-resistant cells due to lack of drug efflux. ${ }^{94}$

The development of multifunctional magnetic nanoparticle formulations further boosts the potential use of SPIONs in medicine. These formulations not only serve the purpose of being drug delivery vectors but also have applications in MRI imaging, ${ }^{95}$ targeted thermosensitive chemotherapy, ${ }^{96}$ magnetically targeted photodynamic therapy, ${ }^{97}$ and fluorescent/luminescence imaging. ${ }^{98}$ Yallapu et al developed water-dispersible SPIONs for hyperthermia, MRI, and drug delivery applications. SPIONs were prepared by precipitation of iron salts in the presence of ammonia and coated with $\beta$-cyclodextrin and a Pluronics polymer. Multilayer $\beta$-cyclodextrin and Pluronics polymer-coated magnetic nanoparticles were found to have good stability, enhanced cellular uptake, and sustained release of encapsulated curcumin, an anticancer drug. This formulation showed improved MRI characteristics with enhanced therapeutic anticancer activity. Due to its good dispersibility, this formulation also has excellent heating effects on application of an alternating magnetic field, making it suitable for localized treatment of cancer using hyperthermia. Further, the formulation was found to be hemocompatible, making it an excellent approach for drug delivery. ${ }^{99}$ In another study, Yang et al prepared multifunctional wormlike vesicles simultaneously loaded with SPIONs and doxorubicin for targeted cancer therapy and ultrasensitive MRI. Stable wormlike polymer vesicles were formed by heterofunctional triblock polymer R (methoxy or FA)-PEG ${ }_{114}$ - $\mathrm{PLA}_{\mathrm{x}}-\mathrm{PEG}_{46}$-acrylate via a double-emulsion method. The outer surface consisted of long hydrophilic polyethylene glycol chains bearing methoxy/folate groups, thereby providing active tumor targeting, while the inner surface was formed by short hydrophilic polyethylene glycol chains bearing the acrylate group which were cross-linked via free radical polymerization to provide enhanced in vivo stability. SPIONs were encapsulated in the aqueous inner core with a loading efficiency of $48.0 \mathrm{wt} \%$ while doxorubicin, the hydrophobic drug, was loaded into the hydrophobic membranes of the wormlike vesicles, with a loading efficiency of $9 \%$. The multifunctional wormlike vesicles showed enhanced cytotoxicity in a HeLa cell line as a result of greater cellular uptake due to folate receptor-mediated endocytosis. Moreover, due to relatively high SPION loading levels as well as clustering of SPIONs in the aqueous core, these wormlike polymeric vesicles demonstrated a much higher $\mathrm{r}_{2}$ relaxivity value than Feridex ${ }^{\circledR}$, a commercially available MRI contrast agent. ${ }^{100}$ Targeted cancer theragnostics seem possible with the development of such multifunctional nanoformulations, thereby paving the way for personalized medicine.

In another approach towards killing malignant cells, radionuclides, particularly $\beta$ emitters, were coupled with SPIONs to induce DNA damage to free radicals, resulting in apoptosis of target cells. ${ }^{101}$ However, incorporation of radionuclides on the SPION surface poses unique problems because of the decaying nature of radiotherapeutics. The challenge here lies in designing an efficient SPIONradiotherapeutic complex, which not only achieves a high local concentration in malignant cells, but also minimizes interaction between the radioactive agents and healthy cells in the body. The development of this technique could greatly reduce exposure to radiation and its associated side effects in external radiotherapy covering the whole body.

A drug-free approach to combating cancer cells involves localized heating of these cells from the inside. Cells begin to show signs of apoptosis when their inside temperature is raised in the range of $41^{\circ} \mathrm{C}-47^{\circ} \mathrm{C}$. Necrosis results when the temperature reaches approximately $50^{\circ} \mathrm{C}$. Targeted hyperthermia involves administration of magnetic nanoparticles, which are taken up by cells through endocytotic pathways and become concentrated in intracellular endosomal vesicles. When subjected to a high frequency AC magnetic field, these particles become heated as a consequence of Neel or Brownian relaxation losses in single-domain particles, resulting in localized killing of these cells. ${ }^{102}$ The main challenge lies in selective delivery of these nanoparticles to tumor cells and optimization of their heating properties for production of sufficient magnetic hyperthermia. At least a ten-fold increase in heating power has been reported, with an increase in particle size of maghemite nanoparticles to $12-14 \mathrm{~nm} .{ }^{103}$ Gonzalez-Fernandez et al showed that $\mathrm{Fe}_{2} \mathrm{O}_{3}$ nanoparticles 
around $30 \mathrm{~nm}$ in size exhibit maximum heating efficiency. Coating tends to decrease heating efficiency, hence should be kept to a minimum. ${ }^{104}$

Magnetoliposomes have also emerged as an effective tool for producing localized hyperthermia together with delivery of encapsulated drugs to the target site, resulting in the destruction of cancerous cells. In order to achieve targeted delivery of methotrexate to skeletal muscle tissue, Zhua et al prepared thermosensitive magnetoliposomes capable of liberating more than $80 \%$ of the encapsulated methotrexate within 30 minutes when the environmental temperature was increased from $37^{\circ} \mathrm{C}$ to $41^{\circ} \mathrm{C}$. The prepared liposomes enabled increased accumulation of methotrexate in musculoskeletal tissue when exposed to an external constant magnetic field and heated to $41^{\circ} \mathrm{C}$. These thermosensitive magnetoliposomes showed good magnetic targeting, with rapid release of the encapsulated drug in response to hyperthermia. ${ }^{105}$ Zhang et al prepared lyophilized negatively charged magnetic liposomes containing paclitaxel for targeting breast carcinoma via parenteral administration. Pharmacokinetic studies showed that these magnetic liposomes were selectively taken up by tumor tissue because of their tendency to migrate exclusively to the tumor mass under the guidance of an external magnetic field. The antitumor efficacy of the prepared formulation was found to be better than that of a commercially available paclitaxel formulation containing Cremophor $^{\circledR}$ EL and ethanol. In addition, the half-life of paclitaxel was reported to be increased to 19.37 hours for the magnetoliposomes versus 4.11 hours for the commercially available formulation. Paclitaxel-loaded magnetic liposomes offered targeted delivery of a chemotherapeutic drug to its site of action with significant anticancer activity and fewer side effects. ${ }^{106}$

Apart from therapy, the concept of "magnetic cells" (magnetic nanoparticles when endocytosed in cells) is providing new approaches for cellular manipulation in response to different applied magnetic fields. ${ }^{107}$ These manipulations can be used to deform internal cellular membranes or to alter the cell architecture.

\section{Treatment of arthritis}

Corticosteroids are the mainstay of therapy for patients with arthritis. Intra-articular injections of corticosteroids provide symptomatic treatment but have severe limitations, including development of crystal-induced arthritis as well as increasing the risk of articular infection, particularly on repeated injection. Development of SPION-corticosteroid conjugates could be a potential solution to these problems.
Moreover, with the application of an external magnetic field, these magnetic conjugates could be retained for a longer time at their desired site of action, by delaying their uptake by macrophages or lymphatic drainage. ${ }^{108}$ Polyvinyl alcohol-SPIONs and their fluorescently functionalized analogs, ie, amino-polyvinyl alcohol-Cy2.5 SPIONs, were injected intra-articularly or periarticularly in the stifle and carpometaphalangeal joints of sheep and targeted using a permanent $\mathrm{NdFeB}$ magnet. ${ }^{109}$ The results confirmed the biocompatibility of these nanoparticles, which were found to remain within the synovial membrane for a period of 5 days, demonstrating their potential applicability in prolonging the action of medication applied intra-articularly. SPIONs and dexamethasone acetate coencapsulated into polylactic-co-glycolic acid microparticles can also serve as a targeted delivery system for the treatment of joint-related pathologies. These microparticles have been found to be biocompatible with synoviocytes. ${ }^{108,110}$

\section{Gene therapy}

The biotechnology industry aims at providing gene-based therapy to treat otherwise incurable diseases. Expression of desired genes (sense technology) and silencing of expression of troubling genes (siRNA technology) are the two basic approaches of gene therapy. The main concern arises in successful delivery of these gene-based drugs to their site of action, while maintaining their integrity and stability. The conventional approach involves delivery of the desired genes with the help of viral vectors. However, this approach raises a lot of safety concerns. Alternative strategies utilize cationic delivery systems which can form complexes electrostatically with negative charged DNA. ${ }^{111}$ SPIONs coated with cationic polymers have been found to increase the magnetofection efficiency of therapeutic genes. PEI-coated SPIONs interact with DNA to form cation-anion complexes which are taken up into cells by endocytosis. Via the proton sponge effect, DNA-PEI-SPION complexes evade the endosomal barrier and deliver the gene of interest to the nucleus. Use of permanent magnets and a pulsating magnetic field enables enhanced transfection efficiency due to reduced free diffusion of these particles. DNA-PEI-SPION complexes also show reduced toxicity compared with PEI-DNA complexes. ${ }^{42}$ Namgung et al designed thermally crosslinked superparamagnetic nanoparticles containing polyethylene glycol, covalently bonded to branched PEI and complexed with DNA of interest. This hybrid conjugate demonstrated high transfection efficiency in vascular endothelial cells; successfully inhibiting the 
expression of plasminogen activator inhibitor-1 involved in various vascular disorders, including vascular inflammation and atherosclerosis. ${ }^{112}$ Hwang et al immobilized an adenoassociated virus delivery system on heparin-coated SPIONs. The magnetically guided adenoassociated virus delivery system was found to infect target cells efficiently and rapidly, opening up new avenues for use of SPIONs in a variety of gene therapy applications. ${ }^{113}$

\section{Stem cell therapy}

Stem cell therapy involves transplantation of stem cells to an injured tissue site, where these cells grow, differentiate, and take over the function of the injured tissue. However, this therapy involves extensive diagnostic and surgical intervention. SPIONs have emerged as an attractive tool for the labeling and delivery of stem cells to desired sites. Stem cells labeled with SPIONs can easily be tracked using MRI. This provides a useful noninvasive method for tracking the destination of transplanted cells in vivo. ${ }^{14,115}$ The increasing use of SPIONs in the labeling of stem cells is due primarily to the following advantages associated with their use: SPIONs show good contrast enhancement in MRI as a result of their high magnetic susceptibility; they are biocompatible, as demonstrated by the SPION-based contrast agents approved by the US Food and Drug Administration and currently on the market; and the ample opportunity for modification of their surface architecture, thus allowing labeling of different types of stem cells. Stem cells can be labeled with SPIONs by several methods. First, they can be labeled by prolonged incubation with SPIONs, resulting in passive accumulation of the contrast agent within the cell. However, this method does not ensure efficient labeling, because uptake is limited by the phagocytic behavior of the cells being labeled. ${ }^{116}$ Second, coupling of transfection agents like Superfect ${ }^{\circledR}$, poly-L-lysine, protamine, and Lipofectamine ${ }^{\circledR}$ with SPIONs can strongly increase the efficiency of stem cell labeling. ${ }^{117-119}$ Third, a magnetic field can be used to increase membrane permeability transiently, resulting in accumulation of SPIONs within the cells. ${ }^{120}$ However, stem cells can also be labeled by conjugating SPIONs to their cellular surface.

MRI can help to determine the behavior of SPIONlabeled stem cells in vivo, particularly their migration and potential transformation into desired specialized cells within a targeted structure. Gathering of such information will help to bridge our serious lack of understanding of the behavior of stem cells following transplantation. This will pave the way for clinical use of cell therapy. SPIONs with differ- ent surface architectures have been employed for efficient labeling of stem cells. For instance, Horak et al prepared mannose-modified iron oxide particles using a coprecipitation method for labeling of stem cells. Intracellular uptake of mannose-modified SPIONs into rat bone marrow stromal cells was confirmed using optical and transmission electron microscopy. Due to high relaxivity, which is responsible for the contrast in MRI and easy internalization into cells, these mannose-modified iron oxide nanoparticles could serve as an important tool for diagnostic and therapeutic applications in cell-based therapy. ${ }^{121}$ In a similar study, Babic et al evaluated the potential of poly-L-lysine at molecular weights of 146-579,000 as a coating to increase intracellular uptake of SPIONs in rat bone marrow mesenchymal cells. Their results showed that poly-L-lysine of high molecular weight $(38,100)$ was a highly effective surface modifier for achieving optimal internalization by rat bone marrow stromal cells. Nanoparticles were found to localize within the endosomal and lyzosomal compartments, and cellular uptake was found to be dependent on the poly-L-lysine concentration used to modify the iron oxide nanoparticles. Such nanoparticles could serve as a promising tool for noninvasive tracking of transplanted cells in vivo. ${ }^{122}$

Apart from being used to label stem cells, SPIONs can also be used as potential carriers to deliver stem cells to their target site. Yang et al biofunctionalized SPIONs with two kinds of ligands, one specific for stem cells (cluster designation 34) and another for infarcted myocardium. The findings showed that SPIONs functionalized in this way can be guided effectively by an external magnetic field to deliver stem cells to infarcted myocardium. ${ }^{123}$

SPIONs can be multifunctionalized using fluorescent and isotope labeling, thus combining optical and nuclear imaging with MRI. Such an approach holds great promise in validating cellular behavior in vivo. In an interesting study conducted by Lewin et al, SPIONs $5 \mathrm{~nm}$ in size were surface-coated with cross-linked aminated dextran, leading to an overall increase in size to $45 \mathrm{~nm}$. These iron oxide nanoparticles were then conjugated with a fluorescent-labeled internalization ligand, ie, fluorescein isothiocyanate-derivatized HIV-TAT peptide. In order to impart nuclear characteristics, the dextran coating was reacted with a chelator, diethylenetriamine penta-acetic acid, and labeling of the nanoparticles with the ${ }^{111}$ In isotope. These triple-labeled (magnetic, fluorescent and nuclear) SPIONs were found to be taken up efficiently by hematopoietic stem and neural progenitor cells. The modified SPIONs were found to have no effect on the viability and differentiation capacity of hematopoietic stem cells. ${ }^{124}$ 


\section{Pitfalls of using SPIONs as drug delivery vehicles \\ Creating a suitable magnetic field gradient}

A major consideration in successful implementation of SPIONs in therapy is development of a suitable magnetic field gradient for effective localization of SPIONs in target tissue, and their efficient internalization within the desired cells. Blood flow in the arteries and veins offers resistance to the development of a magnetic field gradient. The magnetic forces applied should be strong enough to overcome this resistance for effective concentration of magnetic nanoparticles at their desired site. ${ }^{2}$

Blood vessels and organs deep within the body cannot be targeted by external magnets because of the lack of an effective magnetic field gradient. As the distance between the magnet and targeted area increases, the strength of the magnetic field at the desired site decreases. Only those areas which are close to the surface can be properly targeted. To overcome this limitation, researchers have been using superconducting magnets, like $\mathrm{SmBaCuO}$ and $\mathrm{YBaCuO}$, which can exert strong magnetic fields. These magnetic fields have been found to penetrate the skin surface to a depth of $20 \mathrm{~mm} \cdot{ }^{125}$ Further, neodymium-iron-boron has been used along with SPIONs to enhance magnetic drug targeting..$^{58,59}$ Magnetic stents or implants, which can create strong local magnetic fields, have also been used to increase the concentration of drug-loaded magnetic nanoparticles at the desired site. ${ }^{126-128}$ However, this approach has limited application because of the surgical procedure involved.

\section{Burst effect}

Another limitation of the use of SPIONs for drug delivery is burst release of drugs grafted onto the SPION surface. Ideally, SPIONs should deliver their entire payload to the site of action. However, lack of proper surface-engineering leads to premature release of a significant proportion of the drug load, which can result in toxicity. Crosslinkable polymers can reduce burst release of drugs to a large extent. SPIONs with a rigid crosslinked polyethylene glycol fumarate coating were found to reduce the burst effect rate by $21 \%$ compared with non-crosslinked tamoxifen nanoparticles. ${ }^{129}$ Mahmoudi et $\mathrm{a}^{205}$ utilized starch to test for improvement in the burst effect of encapsulated theophylline from SPIONs containing superparamagnetic polyurethane microspheres. They found a significant decrease in the burst effect of the drug. This may have been due to entanglement of high molecular weight starch chains with the polyurethane polymer, forming a barrier to diffusion of the drug into the surrounding fluid.

\section{Low bioavailability}

Intravenous administration is the route of choice for SPIONs. Commercially available SPION-based MRI contrast agents are generally given by the intravenous route. Although intravenous administration of these iron oxide nanoparticles ensures $100 \%$ systemic bioavailability, their specific uptake by target cells is an issue of concern because of nonspecific uptake by the reticuloendothelial system and nonspecific binding to plasma proteins. However, with proper surface-engineering and attachment of suitable targeting ligands, along with magnetic focusing, it is possible to enhance the uptake of drug-loaded SPIONs by target tissue. ${ }^{2,16,21,130}$

\section{Interaction with the blood-brain barrier}

The blood-brain barrier is relatively impermeable to a wide variety of drugs due to the presence of tight endothelial junctions. Uncoated SPIONs have demonstrated low brain-targeting efficacy due to their inability to cross the blood-brain barrier. Coating of SPIONs with functionalized polyvinyl alcohol, especially amino-polyvinyl alcohol, enhances their uptake by isolated brain-derived endothelial and microglial cells. These SPIONs were also found to be biocompatible, producing no inflammatory response in brain-derived cell cultures. ${ }^{131}$ Coating of SPIONs with appropriate polymers combined with application of a strong external magnetic field could lead to development of a potential vector for imaging and treatment of neurodegenerative diseases.

\section{Toxicity considerations}

For every new drug delivery system that shows promise, considerable studies of the pharmacokinetic and toxicity profile must be carried out. These particles are known to be cleared from the body via endogenous metabolic iron pathways. Liu et al evaluated single-dose and repeat-dose toxicity of SPIONs given by subcutaneous injection in mice. Their results confirmed a low hazard potential for SPIONs, with no treatment-related deaths or transient clinical signs. Histopathological evaluation revealed no iron-positive pigments in macrophages from major organs like the liver, lungs, spleen, brain, kidney, and heart. ${ }^{132}$ Similarly, Gupta et al reported SPIONs modified with polyethylene glycol to be nontoxic to human dermal fibroblasts when using the MTT assay. ${ }^{16}$

However, a few reports have suggested some toxicological effects for SPIONs. Iron overload at the target site is considered to be one of the causes of SPION-associated 
toxicity. After digestion of the coating, high levels of bare $\mathrm{Fe}_{2} \mathrm{O}_{3}$ nanoparticles at the target site can cause an imbalance in homeostasis. This can alter cellular responses, leading to DNA damage, an inflammatory response, oxidative stress, genetic changes, disruption of cytoskeletal organization of cells, and cytotoxicity. SPIONs, on internalization within cells, can be digested by lysozymes, resulting in release of free iron. These free iron ions $\left(\mathrm{Fe}^{2+}\right)$ can react with hydrogen peroxide or oxygen in the mitochondria to form very reactive free radicals which can cause genotoxicity. ${ }^{20,133,134}$ SPIONs have also been found to enhance the G2/M phase of the cell cycle. ${ }^{135}$ Further, SPIONs can alter immune function in a dose-dependent manner, as described by Chen et al in an imprinting control region mouse model. ${ }^{10}$

In a study conducted by Mahmoudi et al, the main reason found for SPION-induced toxicity was formation of gas vesicles as a result of local alteration in ionic equilibrium and protein function. Mahmoudi et al developed a modified method for assessing cytotoxicity associated with SPIONs to establish a better correlation between in vitro and in vivo studies. Surface-saturated SPIONs were obtained by preincubation with cell medium for 24 hours. This was done to mimic in vivo conditions, in which many proteins get adsorbed onto SPIONs when they are introduced into the circulation. In contrast with bare SPIONs, preincubated SPIONs induced less cytotoxicity and gas vesicle formation due to fewer adsorption sites available for interaction with proteins and other biomolecules. ${ }^{136}$

\section{Conclusion and future horizons}

As the pharmaceutical field has progressed, a large number of novel drug delivery systems have emerged, and most of them, including SPIONS, are in the nascent developmental stages. However, various factors make SPIONs one of the most promising drug delivery vehicles. They are one of the easiest systems to produce and have shown the best toxicity profile so far. Guidance by external magnets enables a third targeting mechanism, giving them an edge when all three mechanisms work in unison. They have shown potential applications in a wide variety of biomedical fields, both diagnostic and therapeutic. Carcinomas near the body surface, like squamous cell carcinoma, malignant melanoma, Kaposi's sarcoma, and breast carcinoma, are likely to benefit the most from SPION-based therapy because magnetic targeting works best in these regions.

In spite of the above advantages and decades of intensive research, there is still no SPION-based drug delivery product on the market. There are some serious limitations which have to be overcome before a commercially successful product can be launched. Methodologies related to SPION preparation have been improved, but a lot of work still needs to be done on their characterization. With the discovery of supermagnets, it has become possible to create a suitable magnetic field gradient deep inside the skin surface, which can lead to increased targeting capability of SPIONs. However, such a magnetic field can only be used in the hospital setting.

Development of transdermal patches containing magnetic circuitry using supermagnets capable of generating highly penetrating localized magnetic fields could result in enhanced and efficient accumulation of drugs carrying SPIONs at desired sites. This would be particularly beneficial for ambulatory patients and could also increase patient compliance with treatment. Additionally, the complex dosing regimen according to the individual needs of the patient can be carried out by modulation of the magnetic field strength used.

Another aspect in need of monitoring is the burst release effect of SPIONs. Use of crosslinking polymers has demonstrated promising results in controlling the drug release rate. An alternative approach may be incorporation of SPIONs within a polymer matrix that allows retention of their magnetic properties, thus enabling them to be guided by an external magnetic field. The matrix would regulate the release of drug as desired.

Detailed investigation of the pharmacokinetics and biodistribution of SPIONs in vivo should be carried out if these nanoparticles are intended to be translated from benchtop research to clinical practice. Elucidation of the disposition pathways for SPIONs will provide new insights which will help in further improving the desirable characteristics of SPIONs for targeted drug delivery. Toxicological considerations concerning use of SPIONs as drug delivery vehicles warrant further investigation. Interplay of the wide variety of factors involved in this delivery system could lead to development of SPION-associated toxicities. These factors need to be assessed and characterized properly for development of SPIONs with optimum properties for drug delivery. Tremendous research in this direction is addressing these issues, and the positive results so far allow us to hope that the day is not far off when SPIONs will available for treatment rather than just research.

\section{Acknowledgments}

The authors are grateful to the Director of the Central Drug Research Institute, Lucknow, India, Dr TK Chakraborty, for his constant encouragement and support. We are also grateful to Dr DK Majumdar, whose valuable guidance and constant encouragement helped us to complete this review, and to Jasleen Kaur Khurana for editorial assistance. 


\section{Disclosure}

The authors report no conflicts of interest in this work.

\section{References}

1. Freeman MW, Arrott A, Watson JHL. Magnetism in medicine. J Appl Phys. 1960;31:S404.

2. Mahmoudi M, Sant S, Wang B, Laurent S, Sen T. Superparamagnetic iron oxide nanoparticles (SPIONs): development, surface modification and applications in chemotherapy. Adv Drug Deliv Rev. 2011;63(1-2): 24-46.

3. Douziech-Eyrolles L, Marchais H, Herve K, et al. Nanovectors for anticancer agents based on superparamagnetic iron oxide nanoparticles Int J Nanomedicine. 2007;2(4):541-550.

4. Dave SR, Gao X. Monodispersed magnetic nanoparticles for biodetection, imaging, and drug delivery: a versatile and evolving technology. Wiley Interdiscip Rev Nanomed Nanobiotechnol. 2009; 1(6):583-609.

5. Kodama RH. Magnetic nanoparticles. J Magn Magn Mater. 1999; 200(1-3):359-372.

6. Amstad E, Zurcher S, Mashaghi A, Wong JY, Textor M, Reimhult E. Surface functionalization of single superparamagnetic iron oxide nanoparticles for targeted magnetic resonance imaging. Small. 2009;5(11):1334-1342.

7. Sengupta S, Sasisekharan R. Exploiting nanotechnology to target cancer. Br J Cancer. 2007;96(9):1315-1319.

8. Ruoslahti E, Bhatia SN, Sailor MJ. Targeting of drugs and nanoparticles to tumors. J Cell Biol. 2010;188(6):759-768.

9. Wu X, Tan Y, Mao H, Zhang M. Toxic effects of iron oxide nanoparticles on human umbilical vein endothelial cells. Int $J$ Nanomedicine. 2010;5:385-399.

10. Chen BA, Jin N, Wang J, et al. The effect of magnetic nanoparticles of $\mathrm{Fe}_{3} \mathrm{O}_{4}$ on immune function in normal ICR mice. Int $J$ Nanomedicine 2010;5:593.

11. Zhang L, Dou YH, Gu HC. Sterically induced shape control of magnetite nanoparticles. J Crystal Growth. 2006;296(2):221-226.

12. Huang X, Li L, Liu T, et al. The shape effect of mesoporous silica nanoparticles on biodistribution, clearance, and biocompatibility in vivo. ACS Nano. 2011;5(7):5390-5399.

13. Fadeel B, Garcia-Bennett AE. Better safe than sorry: understanding the toxicological properties of inorganic nanoparticles manufactured for biomedical applications. Adv Drug Deliv Rev. 2010;62(3):362-374.

14. Mahmoudi M, Simchi A, Milani AS, Stroeve P. Cell toxicity of superparamagnetic iron oxide nanoparticles. $J$ Colloid Interface Sci. 2009;336(2):510-518.

15. Chouly C, Pouliquen D, Lucet I, Jeune JJ, Jallet P. Development of superparamagnetic nanoparticles for MRI: effect of particle size, charge and surface nature on biodistribution. J Microencapsul. 1996 13(3):245-255.

16. Gupta AK, Wells S. Surface-modified superparamagnetic nanoparticles for drug delivery: preparation, characterization, and cytotoxicity studies. IEEE Trans Nanobioscience. 2004;3(1):66-73.

17. Sjogren CE, Johansson C, Naevestad A, Sontum PC, Briley-Saebo K, Fahlvik AK. Crystal size and properties of superparamagnetic iron oxide (SPIO) particles. Magn Reson Imag. 1997;15(1): $55-67$.

18. Nunes AC, Yu ZC. Fractionation of a water-based ferrofluid. J Magn Magn Mater. 1987;65(2-3):265-268.

19. Williams S, Lee H, Turner MM. Size characterization of magnetic cell sorting microbeads using flow field-flow fractionation and photon correlation spectroscopy. J Magn Magn Mater. 1999;194(1-3): 248-253.

20. Gupta AK, Gupta M. Cytotoxicity suppression and cellular uptake enhancement of surface modified magnetic nanoparticles. Biomaterials. 2005;26(13):1565-1573

21. Veiseh O, Gunn JW, Zhang M. Design and fabrication of magnetic nanoparticles for targeted drug delivery and imaging. Adv Drug Deliv Rev. 2010;62(3):284-304.
22. Harris JM, Chess RB. Effect of pegylation on pharmaceuticals. Nat Rev Drug Discov. 2003;2(3):214-221.

23. Ganguly A, Kundu R, Ramanujachary KV, et al. Role of carboxylate ion and metal oxidation state on the morphology and magnetic properties of nanostructured metal carboxylates and their decomposition products. J Chem Sci. 2008;120(6):521-528.

24. Tartaj P, Morales MP, Veintemillas-Verdaguer S, González-Carreno T, Serna CJ. The preparation of magnetic nanoparticles for applications in biomedicine. J Phys D Appl Phys. 2003;36:R182.

25. LaMer VK, Dinegar RH. Theory, production and mechanism of formation of monodispersed hydrosols. J Am Chem Soc. 1950;72(11): $4847-4854$

26. Den Ouden CJJ, Thompson RW. Analysis of the formation of monodisperse populations by homogeneous nucleation. $J$ Colloid Interface Sci. 1991;143(1):77-84.

27. Rodriguez-Clemente R, Lopez-Macipe A, Gomez-Morales J, TorrentBurgues J, Castano VM. Hydroxyapatite precipitation: a case of nucleation-aggregation-agglomeration-growth mechanism. J Eur Ceram Soc. 1998;18(9):1351-1356.

28. Tartaj P, Morales MP, Gonzalez-Carreno T, Veintemillas-Verdaguer S, Serna CJ. Advances in magnetic nanoparticles for biotechnology applications. J Magn Magn Mater. 2005;290:28-34.

29. Sugimoto T, Matijevic E. Formation of uniform spherical magnetite particles by crystallization from ferrous hydroxide gels. $J$ Colloid Interface Sci. 1980;74(1):227-243.

30. Massart R. Preparation of aqueous magnetic liquids in alkaline and acidic media. IEEE Trans Magn. 1981;17(2):1247-1248.

31. Goikolea E, Insausti M, Lezama L, Gil de Muro I, Garitaonandia JS. Magnetic and structural characterization of silver-iron oxide nanoparticles obtained by the microemulsion technique. J Non Cryst Solids. 2008;354(47-51):5216-5218.

32. Sun S, Zeng H. Size-controlled synthesis of magnetite nanoparticles. J Am Chem Soc. 2002;124(28):8204-8205.

33. Strable E, Bulte JWM, Moskowitz B, Vivekanandan K, Allen M, Douglas T. Synthesis and characterization of soluble iron oxidedendrimer composites. Chem Mater. 2001;13(6):2201-2209.

34. Vijayakumar R, Koltypin Y, Felner I, Gedanken A. Sonochemical synthesis and characterization of pure nanometer-sized $\mathrm{Fe}_{3} \mathrm{O}_{4}$ particles. Mater Sci Eng A. 2000;286(1):101-105.

35. Dang F, Enomoto N, Hojo J, Enpuku K. A novel method to synthesize monodispersed magnetite nanoparticles. Chem Lett. 2008;37(5):530-531.

36. Veintemillas-Verdaguer S, Morales MP, Serna CJ. Effect of the oxidation conditions on the maghemites produced by laser pyrolysis Appl Organomet Chem. 2001;15(5):365-372.

37. Matsunaga T, Okamura Y, Tanaka T. Biotechnological application of nano-scale engineered bacterial magnetic particles. J Mater Chem. 2004;14(14):2099-2105.

38. Schuler D, Frankel RB. Bacterial magnetosomes: microbiology, biomineralization and biotechnological applications. Appl Microbiol Biotechnol. 1999;52(4):464-473.

39. Meldrum FC, Heywood BR, Mann S. Magnetoferritin: in vitro synthesis of a novel magnetic protein. Science. 1992;257(5069):522.

40. Wong KKW, Douglas T, Gider S, Awschalom DD, Mann S. Biomimetic synthesis and characterization of magnetic proteins (magnetoferritin). Chem Mater. 1998;10(1):279-285.

41. Petri-Fink A, Chastellain M, Juillerat-Jeanneret L, Ferrari A, Hofmann H. Development of functionalized superparamagnetic iron oxide nanoparticles for interaction with human cancer cells. Biomaterials. 2005;26(15):2685-2694.

42. Steitz B, Hofmann H, Kamau SW, et al. Characterization of PEI-coated superparamagnetic iron oxide nanoparticles for transfection: size distribution, colloidal properties and DNA interaction. J Magn Magn Mater. 2007;311(1):300-305.

43. Hildebrandt N, Hermsdorf D, Signorell R, Schmitz SA, Diederichsena U. Superparamagnetic iron oxide nanoparticles functionalized with peptides by electrostatic interactions. ARKIVOC. 2007;79:90. 
44. Skouras A, Mourtas S, Markoutsa E, et al. Magnetoliposomes with high USPIO entrapping efficiency, stability and magnetic properties. Nanomedicine. 2011;7(5):572-579.

45. Mulder WJM, Strijkers GJ, van Tilborg GAF, Griffioen AW, Nicolay K. Lipid-based nanoparticles for contrast-enhanced MRI and molecular imaging. NMR Biomed. 2006;19(1):142-164.

46. Bulte JW, Ma LD, Magin RL, et al. Selective MR imaging of labeled human peripheral blood mononuclear cells by liposome mediated incorporation of dextran-magnetite particles. Magn Reson Med. 1993;29(1):32-37.

47. Yang J, Lee TI, Lee J, et al. Synthesis of ultrasensitive magnetic resonance contrast agents for cancer imaging using PEG-fatty acid. Chem Mater. 2007;19(16):3870-3876.

48. De Cuyper M, Joniau M. Magnetoliposomes. Formation and structural characterization. Eur Biophys J. 1988;15(5):311-319.

49. Bulte JWM, Benâ Hur T, Miller BR, et al. MR microscopy of magnetically labeled neurospheres transplanted into the Lewis EAE rat brain. Magn Reson Med. 2003;50(1):201-205.

50. Walter GA, Cahill KS, Huard J, et al. Noninvasive monitoring of stem cell transfer for muscle disorders. Magn Reson Med. 2004;51(2): 273-277.

51. Lee I, Bulte JWM, Schweinhardt P, et al. In vivo magnetic resonance tracking of olfactory ensheathing glia grafted into the rat spinal cord. Exp Neurol. 2004;187(2):509-516.

52. Lamanna G, Kueny-Stotz M, Mamlouk-Chaouachi H, et al. Dendronized iron oxide nanoparticles for multimodal imaging. Biomaterials. 2011;32(33):8562-8573.

53. Danhier F, Feron O, Preat V. To exploit the tumor microenvironment: Passive and active tumor targeting of nanocarriers for anti-cancer drug delivery. J Control Release. 2010;148(2):135-146.

54. Maeda H, MatsumuraY. Tumoritropic and lymphotropic principles of macromolecular drugs. Crit Rev Ther Drug Carrier Syst. 1989;6(3):193-210.

55. Matsumura $\mathrm{Y}, \mathrm{Maeda} \mathrm{H}$. A new concept for macromolecular therapeutics in cancer chemotherapy: mechanism of tumoritropic accumulation of proteins and the antitumor agent smancs. Cancer Res. 1986;46(12 Pt 1): 6387-6392.

56. Acharya S, Sahoo SK. PLGA nanoparticles containing various anticancer agents and tumour delivery by EPR effect. Adv Drug Deliv Rev. 2011;63(3):170-183.

57. Dobson J. Magnetic nanoparticles for drug delivery. Drug Dev Res. 2006;67(1):55-60.

58. Mondalek FG, Zhang YY, Kropp B, et al. The permeability of SPION over an artificial three-layer membrane is enhanced by external magnetic field. J Nanobiotechnology. 2006;4:4

59. Kumar A, Jena PK, Behera S, Lockey RF, Mohapatra S, Mohapatra S. Multifunctional magnetic nanoparticles for targeted delivery. Nanomedicine. 2010;6(1):64-69.

60. Lamkowsky MC, Geppert M, Schmidt MM, Dringen R. Magnetic field-induced acceleration of the accumulation of magnetic iron oxide nanoparticles by cultured brain astrocytes. J Biomed Mater Res A. November 7, 2011. [Epub ahead of print.]

61. Prijic S, Scancar J, Romih R, et al. Increased cellular uptake of biocompatible superparamagnetic iron oxide nanoparticles into malignant cells by an external magnetic field. J Membr Biol. 2010; 236(1):167-179.

62. Corot C, Robert P, Idee JM, Port M. Recent advances in iron oxide nanocrystal technology for medical imaging. Adv Drug Deliv Rev. 2006;58(14):1471-1504.

63. Barry SE. Challenges in the development of magnetic particles for therapeutic applications. Int J Hyperthermia. 2008;24(6):451-466.

64. Gu JL, Xu HF, Han YH, et al. The internalization pathway, metabolic fate and biological effect of superparamagnetic iron oxide nanoparticles in the macrophage-like RAW264. 7 cell. Sci China Life Sci. 2011;54(9): 793-805.

65. Yang CY, Tai MF, Lin CP, et al. Mechanism of cellular uptake and impact of ferucarbotran on macrophage physiology. PLoS One. 2011; 6(9):e25524
66. Hanini A, Schmitt A, Kacem K, Chau F, Ammar S, Gavard J. Evaluation of iron oxide nanoparticle biocompatibility. Int $J$ Nanomedicine. 2011;6:787-794.

67. Wang J, Chen Y, Chen B, et al. Pharmacokinetic parameters and tissue distribution of magnetic $\mathrm{Fe}_{3} \mathrm{O}_{4}$ nanoparticles in mice. Int $J$ Nanomedicine. 2010;5:861-866.

68. Briley-Saebo K, Bjornerud A, Grant D, Ahlstrom H, Berg T, Kindberg GM. Hepatic cellular distribution and degradation of iron oxide nanoparticles following single intravenous injection in rats: implications for magnetic resonance imaging. Cell Tissue Res. 2004; 316(3):315-323.

69. SchlorfT, Meincke M, Kossel E, Gluer CC, Jansen O, Mentlein R. Biological properties of iron oxide nanoparticles for cellular and molecular magnetic resonance imaging. Int J Mol Sci. 2011;12(1):12-23.

70. Arbab AS, Wilson LB, Ashari P, Jordan EK, Lewis BK, Frank JA. A model of lysosomal metabolism of dextran coated superparamagnetic iron oxide (SPIO) nanoparticles: implications for cellular magnetic resonance imaging. NMR Biomed. 2005;18(6):383-389.

71. Levy M, Lagarde F, Maraloiu VA, et al. Degradability of superparamagnetic nanoparticles in a model of intracellular environment: follow-up of magnetic, structural and chemical properties. Nanotechnology. 2010;21(39):395103.

72. Levy M, Luciani N, Alloyeau D, et al. Long term in vivo biotransformation of iron oxide nanoparticles. Biomaterials. 2011; 32(16):3988-3999.

73. Jain TK, Reddy MK, Morales MA, Leslie-Pelecky DL, Labhasetwar V. Biodistribution, clearance, and biocompatibility of iron oxide magnetic nanoparticles in rats. Mol Pharm. 2008;5(2):316-327.

74. Bourrinet $\mathrm{P}$, Bengele $\mathrm{HH}$, Bonnemain B, et al. Preclinical safety and pharmacokinetic profile of ferumoxtran-10, an ultrasmall superparamagnetic iron oxide magnetic resonance contrast agent. Invest Radiol. 2006;41(3):313-324.

75. Weissleder R, Stark DD, Engelstad BL, et al. Superparamagnetic iron oxide: pharmacokinetics and toxicity. AJR Am J Roentgenol. 1989;152(1):167-173.

76. Mahmoudi M, Laurent S, Shokrgozar MA, Hosseinkhani M. Toxicity evaluations of superparamagnetic iron oxide nanoparticles: cell "vision" versus physicochemical properties of nanoparticles. ACS Nano. 2011;5(9):7263-7276.

77. Mahmoudi M, Hofmann H, Rothen-Rutishauser B, Petri-Fink A. Assessing the in vitro and in vivo toxicity of superparamagnetic iron oxide nanoparticles. Chem Rev. 2012;112(4):2323-2338.

78. Neuberger T, Schopf B, Hofmann H, Hofmann M, Von Rechenberg B. Superparamagnetic nanoparticles for biomedical applications: possibilities and limitations of a new drug delivery system. J Magn Magn Mater. 2005;293(1):483-496.

79. Jordan A, Scholz R, Maier-Hauff K, et al. Presentation of a new magnetic field therapy system for the treatment of human solid tumors with magnetic fluid hyperthermia. J Magn Magn Mater. 2001;225(1): 118-126.

80. Hafeli U. Scientific and Clinical Applications of Magnetic Carriers. New York, NY: Plenum Press; 1997.

81. Brown M, Semelka R, Nishino TK. MRI: basic principles and applications. Med Phys. 2004;31:170.

82. Weinstein JS, Varallyay CG, Dosa E, et al. Superparamagnetic iron oxide nanoparticles: diagnostic magnetic resonance imaging and potential therapeutic applications in neurooncology and central nervous system inflammatory pathologies, a review. J Cereb Blood Flow Metab. 2009;30(1):15-35.

83. Sun C, Lee JS, Zhang M. Magnetic nanoparticles in MR imaging and drug delivery. Adv Drug Deliv Rev. 2008;60(11):1252-1265.

84. Rosen JE, Chan L, Shieh DB, Gu FX. Iron oxide nanoparticles for targeted cancer imaging and diagnostics. Nanomedicine. 2012;8(3): 275-290.

85. Peng XH, Qian X, Mao H, Wang AY. Targeted magnetic iron oxide nanoparticles for tumor imaging and therapy. Int J Nanomedicine. 2008;3(3):311. 
86. Stephen ZR, Kievit FM, Zhang M. Magnetite nanoparticles for medical MR imaging. Mater Today (Kidlington). 2011;14(7-8):330-338.

87. Rumenapp C, Gleich B, Haase A. Magnetic nanoparticles in magnetic resonance imaging and diagnostics. Pharm Res. 2012;29(5): $1165-1179$

88. Mahmoudi M, Serpooshan V, Laurent S. Engineered nanoparticles for biomolecular imaging. Nanoscale. 2011;3(8):3007-3026.

89. Liu F, Laurent S, Fattahi H, Van der Elst L, Muller RN.Superparamagnetic nanosystems based on iron oxide nanoparticles for biomedical imaging. Nanomedicine (Lond). 2011;6(3):519-528.

90. Kohler N, Sun C, Fichtenholtz A, Gunn J, Fang C, Zhang M. Methotrexate-immobilized poly (ethylene glycol) magnetic nanoparticles for MR imaging and drug delivery. Small. 2006;2(6):785-792.

91. Alexiou C, Arnold W, Klein RJ, et al. Locoregional cancer treatment with magnetic drug targeting. Cancer Res. 2000;60(23):6641-6648.

92. Cole AJ, David AE, Wang J, Galban CJ, Hill HL, Yang VC. Polyethylene glycol modified, cross-linked starch-coated iron oxide nanoparticles for enhanced magnetic tumor targeting. Biomaterials. 2010;32(8):2183-2193.

93. Yang C, Rait A, Pirollo KF, Dagata JA, Farkas N, Chang EH. Nanoimmunoliposome delivery of superparamagnetic iron oxide markedly enhances targeting and uptake in human cancer cells in vitro and in vivo. Nanomedicine. 2008;4(4):318-329.

94. Kievit FM, Wang FY, Fang C, et al. Doxorubicin loaded iron oxide nanoparticles overcome multidrug resistance in cancer in vitro. $J$ Control Release. 2011;152(1):76-83.

95. Guthi JS, Yang SG, Huang G, et al. MRI-visible micellar nanomedicine for targeted drug delivery to lung cancer cells. Mol Pharm. 2009;7(1):32-40.

96. Pradhan P, Giri J, Rieken F, et al. Targeted temperature sensitive magnetic liposomes for thermo-chemotherapy. $J$ Control Release. 2010;142(1):108-121.

97. Cinteza LO, Ohulchanskyy TY, Sahoo Y, Bergey EJ, Pandey RK, Prasad PN. Diacyl lipid micelle-based nanocarrier for magnetically guided delivery of drugs in photodynamic therapy. Mol Pharm. 2006;3(4):415-423.

98. Wang L, Yang Z, Zhang Y, Wang L. Bifunctional nanoparticles with magnetization and luminescence. J Phys Chem C Nanometer Interfaces. 2009;113(10):3955-3959.

99. Yallapu MM, Othman SF, Curtis ET, Gupta BK, Jaggi M, Chauhan SC. Multi-functional magnetic nanoparticles for magnetic resonance imaging and cancer therapy. Biomaterials. 2011;32:e1890-e1905.

100. Yang X, Grailer JJ, Rowland IJ, et al. Multifunctional SPIO/DOXloaded wormlike polymer vesicles for cancer therapy and MR imaging. Biomaterials. 2010;31(34):9065-9073.

101. Hamoudeh M, Kamleh MA, Diab R, Fessi H. Radionuclide delivery systems for nuclear imaging and radiotherapy of cancer. Adv Drug Deliv Rev. 2008;60(12):1329-1346.

102. Cherukuri P, Glazer ES, Curley SA. Targeted hyperthermia using metal nanoparticles. Adv Drug Deliv Rev. 2010;62(3):339-345.

103. Jordan A, Wust P, Fahling H, John W, Hinz A, Felix R. Inductive heating of ferrimagnetic particles and magnetic fluids: physical evaluation of their potential for hyperthermia. Int $J$ Hyperthermia. 1993;9(1):51-68.

104. Gonzalez-Fernandez MA, Torres TE, Andrss-Vergas M, et al. Magnetic nanoparticles for power absorption: optimizing size, shape and magnetic properties. J Solid State Chem. 2009;182(10): 2779-2784.

105. Zhua L, Huo Z, Wang L, Tong X, Xiao Y, Ni K. Targeted delivery of methotrexate to skeletal muscular tissue by thermosensitive magnetoliposomes. Int J Pharm. 2009;370(1-2):136-143.

106. Zhang JQ, Zhang ZR, Yang H, Tan QY, Qin SR, Qiu XL. Lyophilized paclitaxel magnetoliposomes as a potential drug delivery system for breast carcinoma via parenteral administration: in vitro and in vivo studies. Pharm Res. 2005;22(4):573-583.

107. Wilhelm C, Gazeau F. Magnetic nanoparticles: internal probes and heaters within living cells. J Magn Magn Mater. 2009;321(7): $671-674$.
108. Butoescu N, Seemayer CA, Foti M, Jordan O, Doelker E. Dexamethasone-containing PLGA superparamagnetic microparticles as carriers for the local treatment of arthritis. Biomaterials. 2009;30(9): 1772-1780.

109. Schulze K, Koch A, Schapf B, et al. Intraarticular application of superparamagnetic nanoparticles and their uptake by synovial membrane: an experimental study in sheep. J Magn Magn Mater. 2005;293(1):419-432.

110. Butoescu N, Jordan O, Burdet P, et al. Dexamethasone-containing biodegradable superparamagnetic microparticles for intra-articular administration: physicochemical and magnetic properties, in vitro and in vivo drug release. Eur J Pharm Biopharm. 2009;72(3): 529-538.

111. Lungwitz U, Breunig M, Blunk T, Gopferich A. Polyethyleniminebased non-viral gene delivery systems. Eur J Pharm Biopharm. 2005; 60(2):247-266.

112. Namgung R, Singha K, Yu MK, et al. Hybrid superparamagnetic iron oxide nanoparticle-branched polyethylenimine magnetoplexes for gene transfection of vascular endothelial cells. Biomaterials. 2010;31(14):4204-4213.

113. Hwang JH, Lee S, Kim E, et al. Heparin-coated superparamagnetic nanoparticle-mediated adeno-associated virus delivery for enhancing cellular transduction. Int J Pharm. 2011;421(2):397-404.

114. Bulte JWM, Douglas T, Witwer B, et al. Magnetodendrimers allow endosomal magnetic labeling and in vivo tracking of stem cells. Nat Biotechnol. 2001;19(12):1141-1147.

115. Jendelova P, Herynek V, DeCroos J, et al. Imaging the fate of implanted bone marrow stromal cells labeled with superparamagnetic nanoparticles. Magn Reson Med. 2003;50(4):767-776.

116. Doche de Laquintane B, Dousset V, Solanilla A, Petry KG, Ripoche J. Iron particle labeling of haematopoietic progenitor cells: an in vitro study. Biosci Rep. 2002;22(5):549-554.

117. Mailander V, Lorenz MR, Holzapfel V, et al. Carboxylated superparamagnetic iron oxide particles label cells intracellularly without transfection agents. Mol Imaging Biol. 2008;10(3):138-146.

118. Frank JA, Miller BR, Arbab AS, et al. Clinically applicable labeling of mammalian and stem cells by combining superparamagnetic iron oxides and transfection agents. Radiology. 2003;228(2): 480-487.

119. Miyoshi S, Flexman JA, Cross DJ, et al. Transfection of neuroprogenitor cells with iron nanoparticles for magnetic resonance imaging tracking: cell viability, differentiation, and intracellular localization. Mol Imaging Biol. 2005;7(4):286-295.

120. Walczak P, Kedziorek DA, Gilad AA, Lin S, Bulte JWM. Instant MR labeling of stem cells using magnetoelectroporation. Magn Reson Med. 2005;54(4):769-774.

121. Horak D, Babic M, Jendelova P, et al. D-mannose-modified iron oxide nanoparticles for stem cell labeling. Bioconjug Chem. 2007;18(3):635-644.

122. Babic M, Horak D, Trchova M, et al. Poly (L-lysine)-modified iron oxide nanoparticles for stem cell labeling. Bioconjug Chem. 2008;19(3):740-750.

123. Yang SY, Jian ZF, Horng HE, et al. Dual immobilization and magnetic manipulation of magnetic nanoparticles. J Magn Magn Mater. 2008;320(21):2688-2691.

124. Lewin M, Carlesso N, Tung CH, et al. Tat peptide-derivatized magnetic nanoparticles allow in vivo tracking and recovery of progenitor cells. Nat Biotechnol. 2000;18(4):410-414.

125. Takeda S, Mishima F, Fujimoto S, Izumi Y, Nishijima S. Development of magnetically targeted drug delivery system using superconducting magnet. J Magn Magn Mater. 2007;311(1):367-371.

126. Chen H, Ebner AD, Kaminski MD, Rosengart AJ, Ritter JA. Analysis of magnetic drug carrier particle capture by a magnetizable intravascular stent-2: parametric study with multi-wire two-dimensional model. J Magn Magn Mater. 2005;293(1):616-632.

127. Yellen BB, Forbes ZG, Halverson DS, et al. Targeted drug delivery to magnetic implants for therapeutic applications. J Magn Magn Mater. 2005;293(1):647-654. 
128. Rosengart AJ, Kaminski MD, Chen H, Caviness PL, Ebner AD, Ritter JA. Magnetizable implants and functionalized magnetic carriers: a novel approach for noninvasive yet targeted drug delivery. J Magn Magn Mater. 2005;293(1):633-638.

129. Mahmoudi M, Simchi A, Imani M, Haifeli UO. Superparamagnetic iron oxide nanoparticles with rigid cross-linked polyethylene glycol fumarate coating for application in imaging and drug delivery. $J$ Phys Chem C. 2009;113(19):8124-8131.

130. Chomoucka J, Drbohlavova J, Huska D, Adam V, Kizek R, Hubalek J. Magnetic nanoparticles and targeted drug delivering. Pharmacol Res. 2010;62(2):144-149.

131. Cengelli F, Maysinger D, Tschudi-Monnet F, et al. Interaction of functionalized superparamagnetic iron oxide nanoparticles with brain structures. J Pharmacol Exp Ther. 2006;318(1):108-116.

132. Liu SY, Han Y, Yin LP, Long L, Liu R. Toxicology studies of a superparamagnetic iron oxide nanoparticle in vivo. Adv Mater Res. 2008;47:1097-1100.

133. Toyokuni S. Iron-induced carcinogenesis: the role of redox regulation. Free Radic Biol Med. 1996;20(4):553-566.

134. Singh N, Jenkins GJ, Asadi R, Doak SH. Potential toxicity of superparamagnetic iron oxide nanoparticles (SPION). Nano Rev. September 21, 2010. [Epub ahead of print.]

135. Mahmoudi M, Simchi A, Vali H, et al. Cytotoxicity and cell cycle effects of bare and oly (vinyl alcohol)-coated iron oxide nanoparticles in mouse fibroblasts. Adv Eng Mater. 2009;11(12):B243-B250.

136. Mahmoudi M, Simchi A, Imani M, et al. A new approach for the in vitro identification of the cytotoxicity of superparamagnetic iron oxide nanoparticles. Colloids Surf B Biointerfaces. 2010;75(1): 300-309.

137. Tartaj P, Morales MP, Veintemillas-Verdaguer S, Gonzalez-Carreno T, Serna CJ. Chapter 5 Synthesis, Properties and Biomedical Applications of Magnetic Nanoparticles. Handbook of magnetic materials. 2006;16:403-482

138. Lu AH, Salabas EL, Schuth F. Magnetic nanoparticles: synthesis, protection, functionalization, and application. Angew Chem Int Ed. 2007;46(8):1222-1244.

139. Qiao R, Yang C, Gao M. Superparamagnetic iron oxide nanoparticles: from preparations to in vivo MRI applications. J Mater Chem. 2009;19(35):6274-6293.

140. Cui H, Feng Y, Ren W, Zeng T, Lv H, Pan Y. Strategies of large scale synthesis of monodispersed nanoparticles. Recent Pat Nanotechnol. 2009;3(1):32-41.

141. Munshi N, De TK, Maitra A. Size modulation of polymeric nanoparticles under controlled dynamics of microemulsion droplets. J Colloid Interface Sci. 1997;190(2):387-391.

142. Xu J, Yang H, Fu W, et al. Preparation and magnetic properties of magnetite nanoparticles by sol-gel method. JMagn Magn Mater. 2007; 309(2):307-311.

143. Pascal C, Pascal JL, Favier F, Moubtassim MLE, Payen C. Electrochemical synthesis for the control of $\mathrm{I}^{3}-\mathrm{Fe}_{2} \mathrm{O}_{3}$ nanoparticle size. Morphology, microstructure, and magnetic behavior. Chem Mater. 1999;11(1):141-147.

144. Abu Mukh-Qasem R, Gedanken A. Sonochemical synthesis of stable hydrosol of $\mathrm{Fe}_{3} \mathrm{O}_{4}$ nanoparticles. J Colloid Interface Sci. 2005;284(2):489-494.

145. Hee Kim E, Sook Lee H, Kook Kwak B, Kim BK. Synthesis of ferrofluid with magnetic nanoparticles by sonochemical method for MRI contrast agent. J Magn Magn Mater. 2005;289:328-330.

146. Liu HL, Ko SP, Wu JH, et al. One-pot polyol synthesis of monosize PVP-coated sub-5 $\mathrm{nm} \mathrm{Fe} \mathrm{O}_{4}$ nanoparticles for biomedical applications. J Magn Magn Mater. 2007;310(2):e815-e817.

147. Cai W, Wan J. Facile synthesis of superparamagnetic magnetite nanoparticles in liquid polyols. J Colloid Interface Sci. 2007;305(2): 366-370.

148. Joseyphus RJ, Kodama D, Matsumoto T, Sato Y, Jeyadevan B, Tohji K. Role of polyol in the synthesis of Fe particles. J Magn Magn Mater. 2007;310(2):2393-2395.
149. Hu F, Li Z, Tu C, Gao M. Preparation of magnetite nanocrystals with surface reactive moieties by one-pot reaction. J Colloid Interface Sci. 2007;311(2):469-474.

150. Hu FQ, Wei L, Zhou Z, Ran YL, Li Z, Gao MY. Preparation of biocompatible magnetite nanocrystals for in vivo magnetic resonance detection of cancer. Adv Mater. 2006;18(19):2553-2556.

151. Li Z, Wei L, Gao MY, Lei H. One-pot reaction to synthesize biocompatible magnetite nanoparticles. Adv Mater. 2005;17(8): 1001-1005.

152. Tartaj P. Probing nanomagnets' interactions inside colloidal superparamagnetic composites: aerosol versus surface template methods. Chem Phys Chem. 2003;4(12):1371-1375.

153. Cirstoiu-Hapca A, Bossy-Nobs L, Buchegger F, Gurny R, Delie F. Differential tumor cell targeting of anti-HER2 (Herceptin) and antiCD20 (Mabthera) coupled nanoparticles. Int J Pharm. 2007;331(2): 190-196.

154. Ren J, Hong HY, Ren TB, Teng XR. Preparation and characterization of magnetic PLA-PEG composite particles. Mater Lett. 2005;59(21): 2655-2658.

155. Zhao H, Saatchi K, Hafeli UO. Preparation of biodegradable magnetic microspheres with poly (lactic acid)-coated magnetite. J Magn Magn Mater. 2009;321(10):1356-1363.

156. Kohler N, Sun C, Wang J, Zhang M. Methotrexate-modified superparamagnetic nanoparticles and their intracellular uptake into human cancer cells. Langmuir. 2005;21(19):8858-8864.

157. Sun C, Sze R, Zhang M. Folic acid-PEG conjugated superparamagnetic nanoparticles for targeted cellular uptake and detection by MRI. J Biomed Mater Res A. 2006;78(3):550-557.

158. Wunderbaldinger P, Josephson L, Weissleder R. Crosslinked iron oxides (CLIO): a new platform for the development of targeted MR contrast agents. Acad Radiol. 2002;9 Suppl 2: S304-S306.

159. Funovics MA, Kapeller B, Hoeller C, et al. MR imaging of the her2/ neu and 9.2. 27 tumor antigens using immunospecific contrast agents. Magn Reson Imaging. 2004;22(6):843-850.

160. Bhattarai SR, Kim SY, Jang KY, et al. Laboratory formulated magnetic nanoparticles for enhancement of viral gene expression in suspension cell line. J Virol Methods. 2008;147(2):213-218.

161. Sun Y, Chen Z, Yang X, Huang P, Zhou X, Du X. Magnetic chitosan nanoparticles as a drug delivery system for targeting photodynamic therapy. Nanotechnology. 2009;20:135102.

162. Schellenberger EA, Hogemann D, Josephson L, Weissleder R. Annexin V-CLIO: a nanoparticle for detecting apoptosis by MRI. Acad Radiol. 2002;9 Suppl 2:S310-S311.

163. Zhang C, Jugold M, Woenne EC, et al. Specific targeting of tumor angiogenesis by RGD-conjugated ultrasmall superparamagnetic iron oxide particles using a clinical 1.5-T magnetic resonance scanner. Cancer Res. 2007;67(4):1555.

164. Yoza B, Matsumoto M, Matsunaga T. DNA extraction using modified bacterial magnetic particles in the presence of amino silane compound. J Biotechnol. 2002;94(3):217-224.

165. Park JO, Rhee KY, Park SJ. Silane treatment of $\mathrm{Fe}_{3} \mathrm{O}_{4}$ and its effect on the magnetic and wear properties of $\mathrm{Fe}_{3} \mathrm{O}_{4}$ /epoxy nanocomposites. Appl Surf Sci. 2010;256(23):6945-6950.

166. Kobayashi H, Matsunaga T. Amino-silane modified superparamagnetic particles with surface-immobilized enzyme. J Colloid Interface Sci. 1991;141(2):505-511.

167. Ma M, Zhang Y, Yu W, Shen HY, Zhang H, Gu N. Preparation and characterization of magnetite nanoparticles coated by amino silane. Colloids Surf A Physicochem Eng Asp. 2003;212(2-3): 219-226.

168. Dilnawaz F, Singh A, Mohanty C, Sahoo SK. Dual drug loaded superparamagnetic iron oxide nanoparticles for targeted cancer therapy. Biomaterials. 2010;31(13):3694-3706.

169. Ahmed AR, Dashevsky A, Bodmeier R. Reduction in burst release of PLGA microparticles by incorporation into cubic phase-forming systems. Eur J Pharm Biopharm. 2008;70(3):765-769. 
170. Suwa T, Ozawa S, Ueda M, Ando N, Kitajima M. Magnetic resonance imaging of esophageal squamous cell carcinoma using magnetite particles coated with anti-epidermal growth factor receptor antibody. Int J Cancer. 1998;75(4):626-634.

171. Lim, II, Njoki PN, Park HY, et al. Gold and magnetic oxide/gold core/ shell nanoparticles as bio-functional nanoprobes. Nanotechnology. 2008;19(30):305102.

172. Gwenin VV, Gwenin CD, Kalaji M. Colloidal gold modified with a genetically engineered nitroreductase: towards a novel enzyme delivery system for cancer prodrug therapy. Langmuir. 2011;27(23):14300-14307.

173. Shubayev VI, Pisanic Ii TR, Jin S. Magnetic nanoparticles for theragnostics. Adv Drug Deliv Rev. 2009;61(6):467-477.

174. Hanessian S, Grzyb JA, Cengelli F, Juillerat-Jeanneret L. Synthesis of chemically functionalized superparamagnetic nanoparticles as delivery vectors for chemotherapeutic drugs. Bioorg Med Chem. 2008;16(6):2921-2931.

175. Antonelli A, Sfara C, Mosca L, Manuali E, Magnani M. New biomimetic constructs for improved in vivo circulation of superparamagnetic nanoparticles. J Nanosci Nanotechnol. 2008;8(5):2270-2278.

176. Gaihre B, Khil MS, Lee DR, Kim HY. Gelatin-coated magnetic iron oxide nanoparticles as carrier system: drug loading and in vitro drug release study. Int J Pharm. 2009;365(1-2):180-189.

177. Lee HY, Lee SH, Xu C et al. Synthesis and characterization of PVP-coated large core iron oxide nanoparticles as an MRI contrast agent. Nanotechnology. 2008;19(16):165101. DOI: 10.1088/09574484/19/16/165101.

178. Wang Z, Guo Y, Li S, Sun Y, He N. Synthesis and characterization of $\mathrm{SiO} 2 /\left(\mathrm{PMMA} / \mathrm{Fe}_{3} \mathrm{O}_{4}\right)$ magnetic nanocomposites. J Nanosci Nanotechnol. 2008;8(4):1797-1802.

179. Kato T, Nemoto R, Mori H, et al. Magnetic microcapsules for targeted delivery of anticancer drugs. Appl Biochem Biotechnol. 1984;10(1):199-211.

180. Patel D, Moon JY, Chang Y, Kim TJ, Lee GH. Poly (D, L-lactideco-glycolide) coated superparamagnetic iron oxide nanoparticles: synthesis, characterization and in vivo study as MRI contrast agent. Colloids Surf A Physicochem Eng Asp. 2008;313:91-94.

181. Do Kyung Kim, Mikhaylova M, Wang FH, et al. Starch-coated superparamagnetic nanoparticles as MR contrast agents. Chem Mater. 2003;15(23):4343-4351.

182. Weissleder R, Mahmood U. Molecular imaging. Radiology. 2001; 219(2):316-333.

183. Weissleder R. Molecular imaging in cancer. Science. 2006;312(5777): 1168-1171

184. Bulte JWM, Kraitchman DL. Iron oxide MR contrast agents for molecular and cellular imaging. NMR Biomed. 2004;17(7):484-499.

185. Schellenberger EA, Sosnovik D, Weissleder R, Josephson L. Magneto/optical annexin V, a multimodal protein. Bioconjug Chem. 2004;15(5):1062-1067.

186. Sosnovik DE, Weissleder R. Emerging concepts in molecular MRI Curr Opin Biotechnol. 2007;18(1):4-10.

187. Tung $\mathrm{CH}$, Mahmood U, Bredow S, Weissleder R. In vivo imaging of proteolytic enzyme activity using a novel molecular reporter. Cancer Res. 2000;60(17):4953-4958.

188. Yang J, Gunn J, Dave SR, Zhang M, Wang YA, Gao X. Ultrasensitive detection and molecular imaging with magnetic nanoparticles. Analyst. 2008;133(2):154-160.
189. Corot C, Petry KG, Trivedi R, et al. Macrophage imaging in central nervous system and in carotid atherosclerotic plaque using ultrasmall superparamagnetic iron oxide in magnetic resonance imaging. Invest Radiol. 2004;39(10):619-625.

190. Trivedi RA. In vivo detection of macrophages in human carotid atheroma. Stroke. 2004;35(7):1631-1635.

191. McCarthy JR, Weissleder R. Multifunctional magnetic nanoparticles for targeted imaging and therapy. Adv Drug Deliv Rev. 2008;60(11): 1241-1251

192. McCarthy JR, Kelly KA, Sun EY, Weissleder R. Targeted delivery of multifunctional magnetic nanoparticles. Nanomedicine (Lond). 2007;2(2):153-167.

193. Semelka RC, Helmberger TKG. Contrast agents for MR imaging of the liver. Radiology. 2001;218(1):27-38.

194. Harisinghani MG, Weissleder R. Sensitive, noninvasive detection of lymph node metastases. PLoS Med. 2004;1(3):e66.

195. Enochs WS, Harsh G, Hochberg F, Weissleder R. Improved delineation of human brain tumors on MR images using a long circulating, superparamagnetic iron oxide agent. J Magn Reson Imaging 1999;9(2):228-232.

196. Neuwelt EA, Varallyay P, Bago AG, Muldoon LL, Nesbit G, Nixon R. Imaging of iron oxide nanoparticles by MR and light microscopy in patients with malignant brain tumours. Neuropathol Appl Neurobiol. 2004;30(5):456-471

197. Claes A, Gambarota G, Hamans B, et al. Magnetic resonance imagingbased detection of glial brain tumors in mice after antiangiogenic treatment. Int J Cancer. 2008;122(9):1981-1986.

198. Berger C, Hiestand P, Kindler Baumann D, Rudin M, Rausch M. Analysis of lesion development during acute inflammation and remission in a rat model of experimental autoimmune encephalomyelitis by visualization of macrophage infiltration, demyelination and blood brain barrier damage. NMR Biomed. 2006;19(1):101-107.

199. Rausch M, Hiestand P, Foster CA, Baumann DR, Cannet C, Rudin M. Predictability of FTY720 efficacy in experimental autoimmune encephalomyelitis by in vivo macrophage tracking: clinical implications for ultrasmall superparamagnetic iron oxide enhanced magnetic resonance imaging. J Magn Reson Imaging. 2004;20(1):16-24.

200. Hoehn M, Wiedermann D, Justicia C, et al. Cell tracking using magnetic resonance imaging. J Physiol. 2007;584(1):25-30.

201. Weber R, Ramos-Cabrer P, Hoehn M. Present status of magnetic resonance imaging and spectroscopy in animal stroke models. J Cereb Blood Flow Metab. 2005;26(5):591-604.

202. Akhtari M, Bragin A, Cohen M, et al. Functionalized magnetonanoparticles for MRI diagnosis and localization in epilepsy. Epilepsia 2008;49(8):1419-1430.

203. Stoll G, Bendszus M. New approaches to neuroimaging of central nervous system inflammation. Curr Opin Neurol. 2010;23(3):282.

204. Mahmoudi M, Sahraian MA, Shokrgozar MA, Laurent S. Superparamagnetic iron oxide nanoparticles: promises for diagnosis and treatment of multiple sclerosis. ACS Chem Neurosci. 2011.

205. Morteza Mahmoudi, Sophie Laurent. Controlling the Burst Effect of a Drug by Introducing Starch in the Structure of Magnetic Polyurethane Microspheres Containing Superparamagnetic Iron Oxide Nanoparticles. Scientia Nanotechnology. 2010;17(1)43-51.

\section{Dovepress}

\section{Publish your work in this journal}

The International Journal of Nanomedicine is an international, peerreviewed journal focusing on the application of nanotechnology in diagnostics, therapeutics, and drug delivery systems throughout the biomedical field. This journal is indexed on PubMed Central, MedLine, CAS, SciSearch $\AA$, Current Contents ${ }^{\circledR} /$ Clinical Medicine,

Journal Citation Reports/Science Edition, EMBase, Scopus and the Elsevier Bibliographic databases. The manuscript management system is completely online and includes a very quick and fair peer-review system, which is all easy to use. Visit http://www.dovepress.com/ testimonials.php to read real quotes from published authors. 